\title{
Dimeric Her2-specific affibody mediated cisplatin-loaded nanoparticles for tumor enhanced chemo-radiotherapy
}

\author{
Haijun Wang ${ }^{1,4 \dagger}$, Dianlong Jia ${ }^{3 \dagger}$, Dandan Yuan ${ }^{5}$, Xiaolei Yin ${ }^{4}$, Fengjiao Yuan ${ }^{6}$, Feifei Wang ${ }^{3}$, Wenna Shi ${ }^{1}$, Hui Li ${ }^{1}$, \\ Li-Min Zhu ${ }^{2^{*}}$ (D) and Qing Fan ${ }^{1^{*}}$
}

\begin{abstract}
Background: Solid tumor hypoxic conditions prevent the generation of reactive oxygen species (ROS) and the formation of DNA double-strand breaks (DSBs) induced by ionizing radiation, which ultimately contributes to radiotherapy (RT) resistance. Recently, there have been significant technical advances in nanomedicine to reduce hypoxia by facilitating in situ $\mathrm{O}_{2}$ production, which in turn serves as a "radiosensitizer" to increase the sensitivity of tumor cells to ionizing radiation. However, off-target damage to the tumor-surrounding healthy tissue by high-energy radiation is often unavoidable, and tumor cells that are further away from the focal point of ionizing radiation may avoid damage. Therefore, there is an urgent need to develop an intelligent targeted nanoplatform to enable precise enhanced RTinduced DNA damage and combined therapy.

Results: Human epidermal growth factor receptor 2 (Her2)-specific dimeric affibody $\left(Z_{\mathrm{Her}_{2}}\right)$ mediated cisplatinloaded mesoporous polydopamine/ $\mathrm{MnO}_{2} /$ polydopamine nanoparticles (Pt@mPDA/MnO $/ 2 / \mathrm{PDA}-\mathrm{Z}_{\mathrm{Her} 2} \mathrm{NPs}$ ) for MRI and enhanced chemo-radiotherapy of Her2-positive ovarian tumors is reported. These NPs are biodegradable under a simulated tumor microenvironment, resulting in accelerated cisplatin release, as well as localized production of $\mathrm{O}_{2}$. $Z_{\text {Her2 }}$, produced using the E. coli expression system, endowed NPs with Her2-dependent binding ability in Her2positive SKOV-3 cells. An in vivo MRI revealed obvious $T_{1}$ contrast enhancement at the tumor site. Moreover, these NPs achieved efficient tumor homing and penetration via the efficient internalization and penetrability of $Z_{\text {Her. }}$. These NPs exhibited excellent inhibition of tumor growth with X-ray irradiation. An immunofluorescence assay showed that these NPs significantly reduced the expression of HIF-1 a and improved ROS levels, resulting in radiosensitization.
\end{abstract}

Conclusions: The nanocarriers described in the present study integrated Her2 targeting, diagnosis and RT sensitization into a single platform, thus providing a novel approach for translational tumor theranostics.

Keywords: Mesoporous polydopamine, $\mathrm{MnO}_{2}$, Dimeric Her2-specific affibody, Tumor hypoxia, Radiosensitization

*Correspondence: Izhu@dhu.edu.cn; qingfan0708@yahoo.com ${ }^{+}$Haijun Wang and Dianlong Jia contributed equally to this work ${ }^{1}$ Department of Pharmacy, Shandong Cancer Hospital and Institute, Shandong First Medical University and Shandong Academy of Medical Sciences, Jinan 250117, China

${ }^{2}$ College of Chemistry, Chemical Engineering and Biotechnology, Donghua University, Shanghai 201620, China

Full list of author information is available at the end of the article

\section{Background}

Radiotherapy (RT), or the precise application of high energy ionizing radiation at the tumor site, can directly induce DNA breakages in tumor cells and/or indirectly damage tumor cells by generating reactive oxygen species (ROS) via water radiolysis and is an important tumor treatment strategy $[1,2]$. More than $60 \%$ of malignant tumor patients receive RT at some stage during their illness, and $40 \%$ of the treatments are successful $[3,4]$.

(C) The Author(s) 2021. This article is licensed under a Creative Commons Attribution 4.0 International License, which permits use, sharing, adaptation, distribution and reproduction in any medium or format, as long as you give appropriate credit to the original author(s) and the source, provide a link to the Creative Commons licence, and indicate if changes were made. The images or other third party material in this article are included in the article's Creative Commons licence, unless indicated otherwise in a credit line to the material. If material is not included in the article's Creative Commons licence and your intended use is not permitted by statutory regulation or exceeds the permitted use, you will need to obtain permission directly from the copyright holder. To view a copy of this licence, visit http://creativeco mmons.org/licenses/by/4.0/. The Creative Commons Public Domain Dedication waiver (http://creativecommons.org/publicdomain/ zero/1.0/) applies to the data made available in this article, unless otherwise stated in a credit line to the data. 
However, the tumor microenvironment (TME) is complex and can contribute to the acquisition of RT resistance. Hypoxic conditions in the solid TME can be ascribed to an imbalance between the supply and consumption of $\mathrm{O}_{2}$ in rapidly proliferating tumor cells, as well as dysfunctional tumor vasculature [5]. The hypoxic TME prevents ROS generation and formation of DNA double-strand breaks (DSBs), which are usually induced by ionizing radiation $[2,5]$, ultimately leading to RT resistance. Furthermore, tumor hypoxic conditions can bring about upregulation of hypoxia-inducible factor $1 \alpha$ (HIF-1 $\alpha$ ), which promotes endothelial cell survival following RT and thus further promotes RT resistance [6].

Traditional medical methods have made use of hyperbaric oxygen inhalation to alleviate hypoxic conditions and improve the tumor concentration of $\mathrm{O}_{2}$, which acts a reservoir of radiation-induced ROS [6-8]. However, the dysfunctional tumor vascular system hinders the delivery of inhaled $\mathrm{O}_{2}$ to the tumor, and the potential for oxygen poisoning, barometric injury, and decompression disease seriously limits the clinical utility of this method [9]. For decades, research has focused on the enhancement of RT efficacy by increasing radiation doses, but the severe side effects caused by excessive high-energy radiation to normal tissue and organs are unavoidable $[5,10]$. Recently, there have been significant technical advances in nanomedicine, such as artificial blood substitutes and nanocatalysts, which relieve hypoxia by intratumoral $\mathrm{O}_{2}$ delivery and/or in situ production of $\mathrm{O}_{2}$ and serve as "radiosensitizers" to treat tumor cells with low and safe doses of ionizing radiation $[10,11]$. For example, Gao et al. developed a perfluorocarbon (PFC)-based nanoscale artificial red blood cell system to relieve tumor hypoxia and thus improve sensitivity to RT. With biomimetic cloaking of the red blood cell membrane, these artificial blood cells effectively delivered $\mathrm{O}_{2}$ into the tumor tissue, greatly relieved hypoxia, and thus remarkably improved the antitumor efficacy of RT [12]. In a recent study, Chen et al. fabricated a catalase-loaded nanoplatform for enhanced RT efficacy. The cargo catalase can trigger rapid decomposition of endogenous hydrogen peroxide $\left(\mathrm{H}_{2} \mathrm{O}_{2}\right)$ into $\mathrm{O}_{2}$ to relieve tumor hypoxia and thus caused enhanced RT efficacy compared to that of X-ray radiation alone [13]. Manganese dioxide $\left(\mathrm{MnO}_{2}\right)$ NPs provide particularly fascinating properties that have been applied for TME-responsive biodegradation, glutathione (GSH)-triggered magnetic resonance imaging (MRI) and serving as a chemodynamic therapeutic agent, which suggests that they have great potential as tumor theranostics [14-16]. Moreover, as an inorganic nanocatalyst, $\mathrm{MnO}_{2}$ possesses the ability to catalyze the generation of $\mathrm{O}_{2}$ by decomposing $\mathrm{H}_{2} \mathrm{O}_{2}$ at the nano level, making $\mathrm{MnO}_{2}$-based agents a promising candidate for improving the efficacy of $\mathrm{O}_{2}$-dependent therapy [17-20]. For example, Yang et al. developed a biodegradable hollow $\mathrm{MnO}_{2}$ nanoplatform for TME-specific MRI and drug release, modulating the hypoxic TME to enhance photodynamic therapy (PDT). Under an acidic TME, these NPs experienced rapid degradation, resulting in the ondemand release of the loaded therapeutic molecules (the photodynamic agent Ce6 and DOX) and the MRI agent $\mathrm{Mn}^{2+}$ and simultaneous induction of decomposition of endogenous $\mathrm{H}_{2} \mathrm{O}_{2}$ into $\mathrm{O}_{2}$ to relieve tumor hypoxia and achieve enhanced PDT efficacy [21].

Despite the superior efficacy of $\mathrm{MnO}_{2}$-based radiosensitizers, the off-target damage to the tumor-surrounding healthy tissue caused by high-energy radiation is often unavoidable [22]. Therefore, there is an urgent need to develop an intelligent, targeted nanoplatform as a "magic bullet" to precisely enhance RT-induced DNA damage with low side effects. One effective approach is to couple these therapeutic formulations with ligands (such as folate, Arg-Gly-Asp tripeptides, and/or hyaluronic acid) [23-25] or antibodies [26-28] that specifically recognize tumor cells or tumor vasculature-associated antigens. This would allow targeted delivery of drugs or radiosensitizers into tumor cells by ligand- or antibody-mediated enhanced endocytosis [29]. However, molecular ligands obtained using chemical approaches have limited affinity for their targets because of their simple structure, and an increasing number of studies have reported the potential immunogenicity of these synthetic agents, which severely impacts their performance [30, 31]. In addition, these agents have relatively poor thermal or chemical stability, poor tumor penetration, and slow blood clearance and are expensive to produce, severely limiting their use [32].

Affibodies, a novel class of non-immunoglobulin-based scaffold proteins, consist of a 58-amino acid residue three-helix bundle $\mathrm{Z}$ domain derived from one of five homologous domains (the B domain) in Staphylococcus aureus protein A [33]. Affibodies can specifically bind to a large range of different target proteins with high affinity by phage display of combinatorial libraries in which typically 13 side-chains on the surface of helices 1 and 2 in the $\mathrm{Z}$ domain have been randomized [34]. Besides the ability to bind different targets, there is no relationship between affibodies and antibodies because of having no sequence or structural homology. Possessing a small molecular weight (only $\sim 6.5 \mathrm{kDa}$ ) and a three-helicalbundle $\mathrm{Z}$ domains, the affibody shows a reversible and rapid folding rate (the folding time is only $3 \mu \mathrm{s}$ ), high thermal tolerance, high specificity, and nanomolar affinities for tumors [35]. Meanwhile, their robust molecular structure endows them with high chemical tolerance, including a wide $\mathrm{pH}$ range (5.5-11) [36]. Moreover, affibodies do not contain disulfide bonds or free cysteines 
intramolecularly, which allows them to be functionally expressed in the reducing environment of the bacterial (i.e., E. coli) cytoplasm at high levels and low cost [37].

Human epidermal growth factor receptor 2 (Her2), which is specifically overexpressed in a significant number of ovarian, gastric and breast cancers, has become a promising target for tumor diagnosis and treatment. Affibodies binding to the extracellular domain of Her2 were previously obtained after phage display selection and these selected affibodies could bind specifically to Her2 but target a different epitope than that targeted by trastuzumab [38]. The original Her2-binding affibody molecule $\mathrm{Z}_{\mathrm{Her2} 24}$ with an affinity of approximately 50 $\mathrm{nM}$ for Her2 was selected for further studies. $Z_{\mathrm{Her2}: 342}$ was developed by the directed combinatorial mutagenesis at the binding site based on sequence of $Z_{\text {Her2:4 }}$ [39]. Compared to $\mathrm{Z}_{\mathrm{Her} 2: 4}$, the Her2-binding affinity of this descendants $Z_{\mathrm{Her} 2: 342}$ increased from $50 \mathrm{nM}$ to $22 \mathrm{pM}$. The $Z_{\text {Her2:342 }}$ was recently further improved by substitution of 11 amino acids in the scaffold and novel Her2 affibody molecule designated $\mathrm{Z}_{\mathrm{Her2} 22891}$ was appeared. After these substitutions, $Z_{\mathrm{Her2}: 2891}$ had higher hydrophilicity, thermal stability, diminished background interactions with immunoglobulins, full production flexibility as well as fully retained in vitro and in vivo functionality [40]. $\mathrm{Z}_{\text {Her2:2891 }}$ has been conjugated with a DOTA moiety (denoted ABY-025) at a unique C-terminal cysteine and these affibodies have been introduced in a series of molecular imaging clinical trials $[41,42]$. Thus, $\mathrm{Z}_{\mathrm{Her2}: 2891}$ is an ideal targeting moiety to construct Her2-targeted drugs for tumor diagnosis and treatment. However, to the best of our knowledge, no $\mathrm{Z}_{\mathrm{Her2} 22891}$ mediated nano-drugs for tumor diagnosis and treatment have been reported to-date. This deficiency promoted us to investigate whether $\mathrm{Z}_{\mathrm{Her} 2 \mathrm{Z}^{891}}$-directed nano-drugs could improve the efficacy of targeted tumor diagnosis and treatment.

Herein, the dimeric Her2-specific affibody-mediated nanoparticles, denoted Pt@mPDA $/ \mathrm{MnO}_{2} / \mathrm{PDA}-\mathrm{Z}_{\mathrm{Her} 2}$ NPs, were developed to enhance MRI imaging and chemo-radiotherapy of Her2-overexpressing ovarian cancer. As shown in Scheme 1, mesoporous polydopamine nanoparticles (mPDA NPs) with high biocompatibility, easy face functionalization, and wet adhesion $[43,44]$ were first prepared by a nanoemulsion assembly method. As some tumor cells at a distance from the focal spot of ionizing radiation may avoid damage, a chemoradiotherapy combination of mPDA NPs involving cisplatin (Pt@mPt NPs) was synthesized. Then, a thin $\mathrm{MnO}_{2}$ layer was grown on the peripheral surface of Pt@mPDA NPs by in situ reduction of $\mathrm{KMnO}_{4}$ to induce endogenous $\mathrm{H}_{2} \mathrm{O}_{2}$ decomposition into $\mathrm{O}_{2}$ and reduce tumor hypoxia. To improve the biocompatibility of the NPs and provide a reactive surface, a biomimetic PDA layer was polymerized on the surface of the $\mathrm{MnO}_{2}$ layer, yielding Pt@mPDA $/ \mathrm{MnO}_{2} / \mathrm{PDA}$ NPs. $\mathrm{Z}_{\mathrm{Her} 2}$ affibodies were ultimately linked to the peripheral PDA layer, resulting in the final intelligent Pt@mPDA/ $\mathrm{MnO}_{2} / \mathrm{PDA}-\mathrm{Z}_{\mathrm{Her} 2} \mathrm{NPs}$. These NPs are expected to provide a suitable means to intelligently target tumor cells and sensitize them to $\mathrm{RT}$, enabling the application of lower doses of radiation and decreasing the damage to the tumor-surrounding healthy tissue. This system has the potential for clinical applications in the treatment of solid tumors, which have thus far evaded the efforts of the medical and scientific community.

\section{Results and discussion}

\section{Preparation and characterization of Pt@mPDA/MnO $2 / P D A$} NPs

Mesoporous PDA (mPDA) NPs were initially synthesized using a nano-emulsion assembly approach. Transmission electron microscopy (TEM) images show that the mPDA NPs are highly uniform with mesostructured morphologies (Fig. 1a) and have a mean size of $119 \mathrm{~nm}$. The mesoporous shape was further characterized by $\mathrm{N}_{2}$ absorption-desorption. As shown in Additional file 1: Fig. S1a and 1b, the surface area and average pore diameter of the mPDA NPs were $36.84 \mathrm{~m}^{2} / \mathrm{g}$ and 2 $\mathrm{nm}$, respectively. After cisplatin loading by electrostatic force between negatively charged mPDA and positively charged cisplatin (Additional file 1: Fig. S1c), a $\mathrm{MnO}_{2}$ layer was formed on the surface of Pt@mPDA NPs, which attributed to the redox reaction between reductive PDA and $\mathrm{KMnO}_{4}$ under neutral conditions. As shown in Fig. 1b, a thin layer on the surface of Pt@mPDA NPs is clearly observed, and the mean size increased to 139 $\mathrm{nm}$. To improve the biocompatibility of the NPs and provide a chemically reactive surface for further functional modification, a biomimetic PDA layer was then polymerized on the surface of the Pt@mPDA/ $\mathrm{MnO}_{2} \mathrm{NPs}$ under weak alkaline conditions ( $\mathrm{pH}$ 8.6). The mean size further increased to $\sim 163 \mathrm{~nm}$, and the mesoporous structure almost disappeared (Fig. 1c).

Step-wise zeta potential changes (Additional file 1: Fig. S1c) were observed, indicating the successful coating of $\mathrm{MnO}_{2}$ and the PDA layer on the NPs. After the final PDA layer surface functionalization, the resulting NPs were denoted Pt@mPDA $/ \mathrm{MnO}_{2} /$ PDA NPs.

The chemical characteristics of the Mn-derived NPs were further examined. Wide scan X-ray photoelectron spectroscopy (XPS) spectra (Additional file 1: Fig. S2a) of the NPs showed the characteristic peaks of C $1 \mathrm{~s}, \mathrm{~N} 1 \mathrm{~s}$, O 1s, and Mn 2p. Mn 2p spectra (Additional file 1: Fig. S2b) showed two characteristic peaks at $653.1 \mathrm{eV}$ and 641.6 $\mathrm{eV}$, which confirm the Mn $2 \mathrm{p}_{3 / 2}$ and $\mathrm{Mn} 2 \mathrm{p}_{1 / 2}$ orbits of 


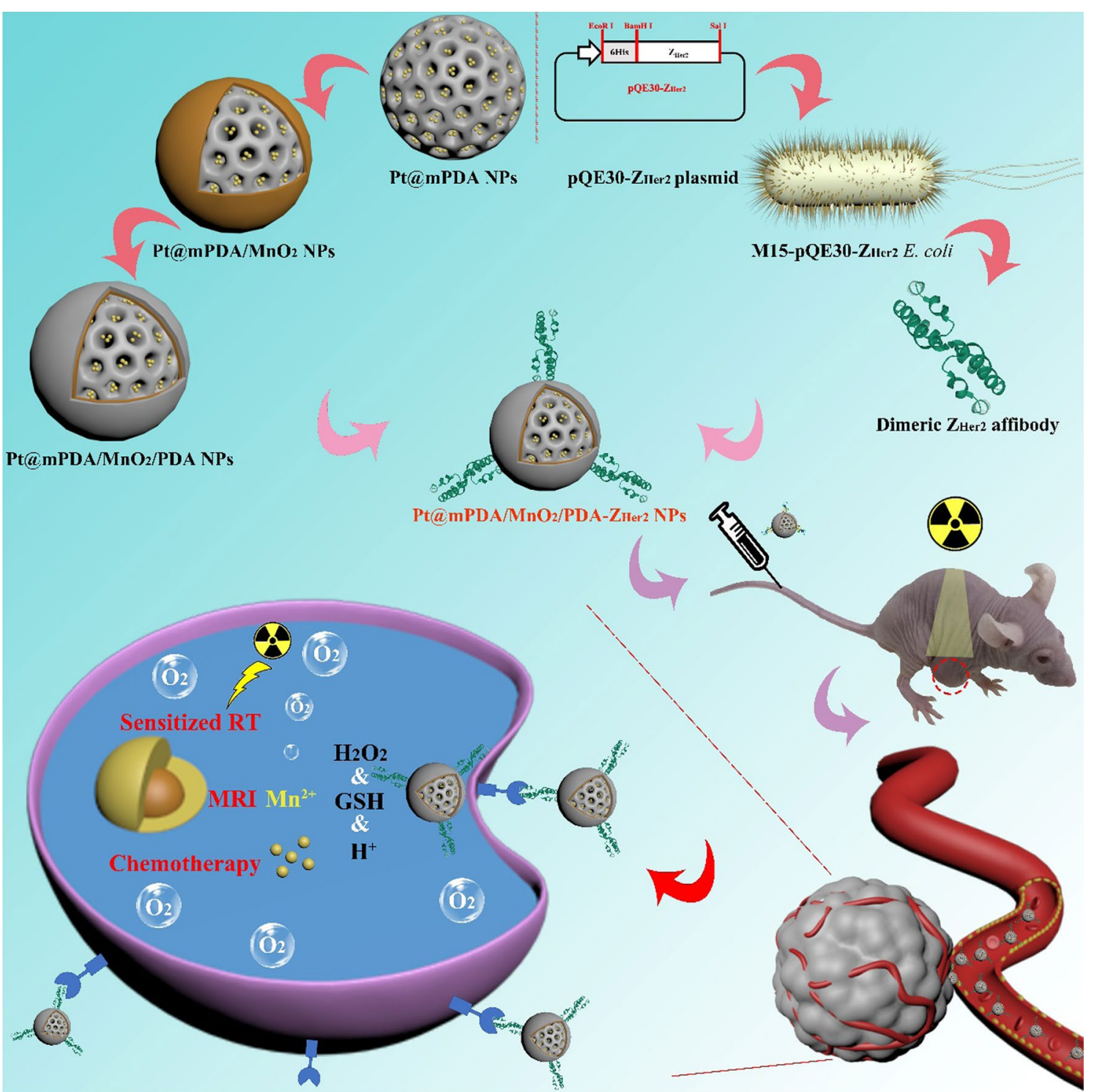

Scheme 1 Experimental workflow for the preparation of Pt@mPDA/MnO $2 / P D A-Z_{\text {Her2 }}$ NPs and in vivo MRI-guided enhanced chemo-radiotherapy

the $\mathrm{Mn}^{4+}$ oxidation state. These results confirm the successful deposition of $\mathrm{MnO}_{2}$ onto the NP surface.

The cisplatin and $\mathrm{MnO}_{2}$ contents of the Pt@mPDA/ $\mathrm{MnO}_{2} / \mathrm{PDA}$ NPs were quantified by inductively coupled plasma-atomic emission spectrometry (ICP-AES) and found to be $\sim 96 \mathrm{mg} / \mathrm{g}$ and $\sim 164 \mathrm{mg} / \mathrm{g}$, respectively. Taken together, these results validate the successful construction of Pt@mPDA $/ \mathrm{MnO}_{2} / \mathrm{PDA}$ NPs.

\section{In vitro degradation and drug release}

The degradation of NPs triggered by $\mathrm{H}_{2} \mathrm{O}_{2}$ and GSH was measured by determining the UV-Vis absorption of Pt@ $\mathrm{mPDA} / \mathrm{MnO}_{2} / \mathrm{PDA} \mathrm{NPs}$ in different media. As shown in Fig. S3, the NPs were stable at neutral pH (Additional file 1: Fig. S3a) but degraded in an $\mathrm{H}_{2} \mathrm{O}_{2}$ - and GSH-sensitive manner, as the absorption decreased over time in PBS containing $1 \mathrm{mM} \mathrm{H}_{2} \mathrm{O}_{2}$ or $2 \mathrm{mM} \mathrm{GSH}$ (Additional file 1: Fig. S3b, c). In striking contrast, the absorption of the dispersed NPs decreased abruptly in a mixture of 1 $\mathrm{mM} \mathrm{H}_{2} \mathrm{O}_{2}$ and $2 \mathrm{mM} \mathrm{GSH}$ (Additional file 1: Fig. S3d), and this decrease was further enhanced after increasing the GSH concentration to $5 \mathrm{mM}$ (Additional file 1: Fig. S3e). After $14 \mathrm{~d}$, the absorbance level of Pt@mPDA/ $\mathrm{MnO}_{2} / \mathrm{PDA}$ NPs in different media was compared. Apparently, the NPs treated with $1 \mathrm{mM} \mathrm{H}_{2} \mathrm{O}_{2}$ and $5 \mathrm{mM}$ GSH showed the greatest degradation degree (Additional 


\section{(See figure on next page.)}

Fig. 1 TEM images of a mPDA, b Pt@mPDA/MnO 2 , and $\mathbf{c}$ Pt@mPDA/MnO $/$ PDA NPs. d-h TEM images of Pt@mPDA/MnO $/$ PDA NPs after incubation in different buffers for 14 days. i The free cisplatin release behavior in PBS (I), and the release profiles of cisplatin from Pt@mPDA/ $\mathrm{MnO}_{2} / \mathrm{PDA}$ NPs under different conditions (II-V). Data are shown as mean \pm S.D. from three independent experiments. $\mathbf{j}$ The relative changes in the concentration of dissolved $\mathrm{O}_{2}$ in different buffers. $\mathbf{k}$ The linear fit of $1 / \mathrm{T}_{1}$ of $\mathrm{mPDA} / \mathrm{MnO}_{2} / \mathrm{PDA}$ NPs without or with $2 \mathrm{mM}$ of GSH and $\mathbf{I}$ the corresponding $\mathrm{T}_{1}$-weighted images with different Mn concentrations

file 1: Fig. S3f). The morphology of the NPs after $14 \mathrm{~d}$ was assessed by TEM (Fig. 1d-h), correspondingly, the NPs treated with $1 \mathrm{mM} \mathrm{H}_{2} \mathrm{O}_{2}$ and $5 \mathrm{mM}$ GSH showed the greatest degree of degradation, revealing $\mathrm{H}_{2} \mathrm{O}_{2}$ - and GSH-sensitive degradation. The former was ascribed to PDA-accelerated degradation in the presence of $\mathrm{H}_{2} \mathrm{O}_{2}$ [45], while the latter was attributed to the redox reaction between the $\mathrm{MnO}_{2}$ layer and GSH [14, 15]. These results suggest that the prepared $\mathrm{mPDA} / \mathrm{MnO}_{2} / \mathrm{PDA} \mathrm{NPs}$ are promising biodegradable materials for TME-specific drug release and in vivo stability.

The release profiles of free cisplatin in PBS (pH 7.4) were firstly measured. The free cisplatin gave a burst of drug release in initial $30 \mathrm{~min}$ of the experiment, and reached a cumulation release of $\sim 93 \%$ after $12 \mathrm{~h}$ (Fig. 1i (I)). In contrast, the Pt@mPDA/ $/ \mathrm{MnO}_{2} / \mathrm{PDA}$ NPs exhibited $\mathrm{H}_{2} \mathrm{O}_{2}, \mathrm{GSH}$, and $\mathrm{pH}$ triple model-responsive drug release (Fig. 1i (II-V)). In blank PBS (pH 7.4), cisplatin was released slowly, with only ca. $\sim 6.6 \%$ of the incorporated cisplatin released after $48 \mathrm{~h}$, while a more rapid and extensive drug release (ca. $27.8 \%$ after $48 \mathrm{~h}$ ) occurred after supplementing with $1 \mathrm{mM} \mathrm{H}_{2} \mathrm{O}_{2}$. In contrast, drug release occurred to a greater extent (ca. $\sim 88 \%$ ) after the addition of $5 \mathrm{mM} \mathrm{GSH}$. These data support the observations of NP degradation under simulated TME conditions. Because of the $\mathrm{pH}$-triggered degradation of $\mathrm{MnO}_{2}$ [21], it was noted that the drug release rate was further accelerated under acidic conditions ( $\mathrm{pH}$ 5.5). In summary, Pt@mPDA/ $\mathrm{MnO}_{2} / \mathrm{PDA}$ NPs exhibit drug release under TME-specific conditions, thus potentially reducing off-target drug leakage.

\section{Decomposition of $\mathrm{H}_{2} \mathrm{O}_{2}$ triggered by NPs and detection of ROS in vitro}

The solid tumor hypoxic microenvironment severely limits the efficacy of RT because the DNA damage and ROS generation induced by ionizing radiation are prevented under hypoxic conditions $[5,6]$. To overcome this problem, NPs containing $\mathrm{MnO}_{2}$ were constructed in order to catalyze the decomposition of $\mathrm{H}_{2} \mathrm{O}_{2}$ to $\mathrm{O}_{2}$. Significant and sustained amounts of $\mathrm{O}_{2}$ were generated after adding $\mathrm{mPDA} / \mathrm{MnO}_{2} / \mathrm{PDA} \mathrm{NPs}\left(\left[\mathrm{MnO}_{2}\right]=2 \mu \mathrm{g} / \mathrm{mL}\right)$ to $\mathrm{PBS}(\mathrm{pH}$ 7.4 and 5.5) containing $\mathrm{H}_{2} \mathrm{O}_{2}$, while PBS with or without $\mathrm{H}_{2} \mathrm{O}_{2}$ in the absence of NPs maintained a stable $\mathrm{O}_{2}$ concentration (Fig. 1j).
A MB degradation method was used to examine the ROS generation. As shown in Additional file 1: Fig. S4, a significant decline in $\mathrm{MB}$ absorbance was observed after treating X-ray (6 Gy), demonstrating that the ROS generation via water molecule radiolysis had occurred. Addition of $\mathrm{MnO}_{2}$-free Pt@mPDA/PDA NPs did not increase the $\mathrm{MB}$ degradation level compared to X-ray treatment, while Pt@mPDA $/ \mathrm{MnO}_{2} / \mathrm{PDA}$ NPs without X-ray treatment had negligible effect on $\mathrm{MB}$ degradation. However, for the $\mathrm{MnO}_{2}$-containing Pt@mPDA/ $\mathrm{MnO}_{2} / \mathrm{PDA} \mathrm{NPs}$ and $\mathrm{X}$-ray combination, the $\mathrm{MB}$ degradation level was increased significantly. These results confirm that the $\mathrm{MnO}_{2}$-containing NPs can enhance radiation-induced ROS generation.

\section{GSH-activated MRI}

The GSH-activated $\mathrm{T}_{1}$-MRI contrast performance of $\mathrm{mPDA} / \mathrm{MnO}_{2} / \mathrm{PDA}$ NPs was investigated with and without GSH. As expected, the NPs showed much stronger $\mathrm{T}_{1}$-weighted MR signal enhancement upon exposure to GSH with a 37.1-fold increase in the $r_{1}$ value compared to the NPs in the absence of GSH (Fig. 1k). Correspondingly, a concentration-dependent brightening effect of mPDA/ $\mathrm{MnO}_{2} / \mathrm{PDA}$ NPs upon treatment with $\mathrm{GSH}$ was observed (Fig. 11), which can be attributed to the GSHactivated MRI agent $\mathrm{Mn}^{2+}$. These results confirm that the $\mathrm{MnO}_{2}$-functionalized NPs are promising candidates for tumor-specific imaging.

\section{Preparation and characterization of Pt@mPDA/ $\mathrm{MnO}_{2} /$ PDA-Z $\mathrm{Z}_{\text {Her2 }}$ NPs}

Since polymerization might improve the stability and avidity of affibodies [46], we first prepared a novel dimeric Her2-binding affibody designated $\mathrm{Z}_{\mathrm{Her} 2}$ (amino acid sequence: mrgshhhhhhgsaeakyakemrnayweiallpnltnqqkrafirklyddpsqssellseakklndsqapkc) based on $\mathrm{Z}_{\mathrm{Her2} 22891}$ through disulfide bond formed by the addition of a cysteine at the $\mathrm{C}$-terminus. The $\mathrm{Z}_{\mathrm{Her} 2}$ affibody was expressed by the $E$. coli expression system and purified using Ni-NTA affinity chromatography. The expected molecular weight of the affibody is approximately $8 \mathrm{kDa}$. Compared to the protein isolated from cells before induction (Fig. 2a, lane 1), a protein with a molecular weight of approximately $10 \mathrm{kDa}$ was induced by IPTG (Fig. 2a, lane 2). Following cell disruption, SDS-PAGE analysis of the total protein in the soluble (Fig. 2a, lane 3) and insoluble 

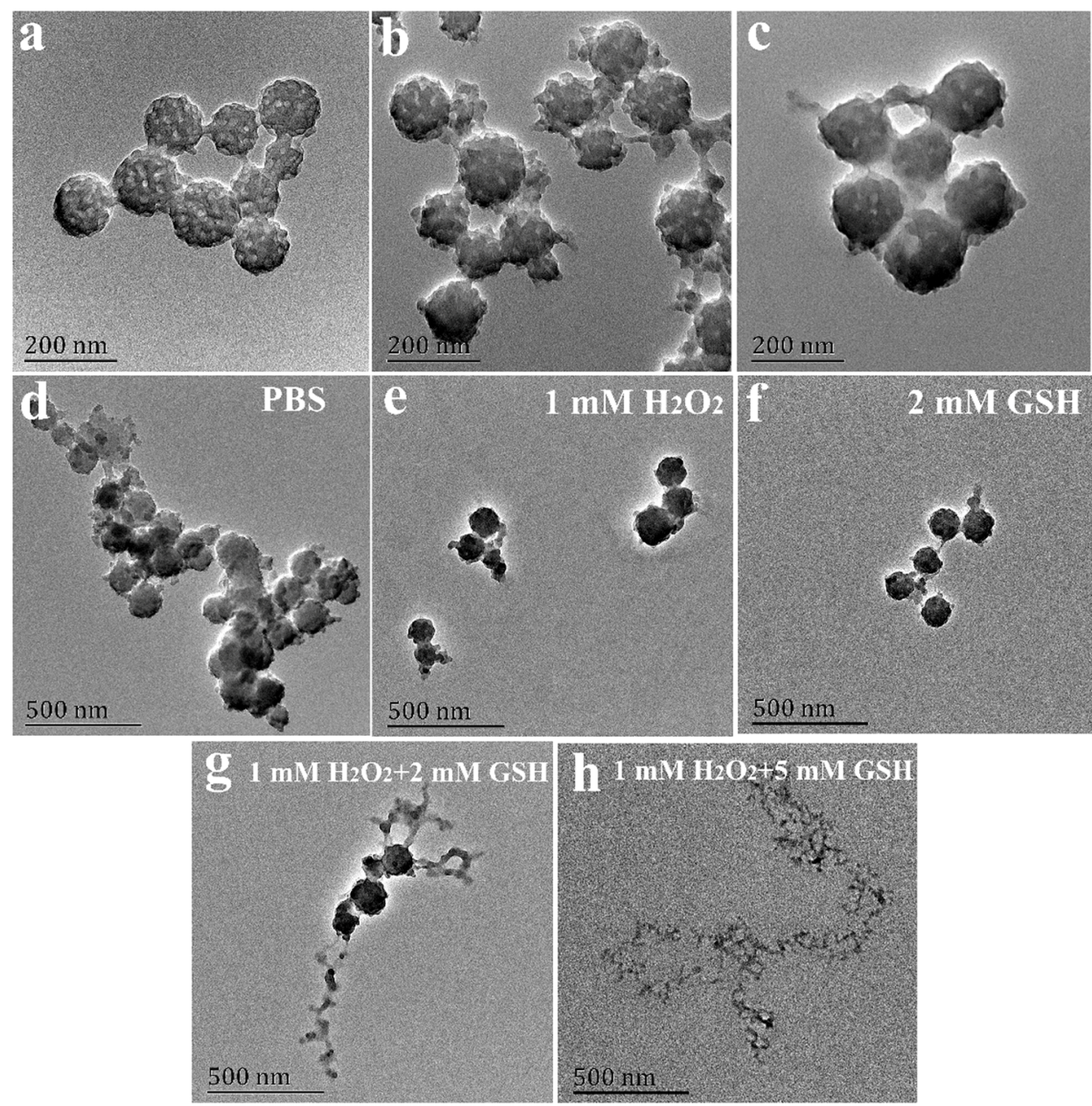

$1 \mathrm{mM} \mathrm{H} \mathrm{H}_{2}$
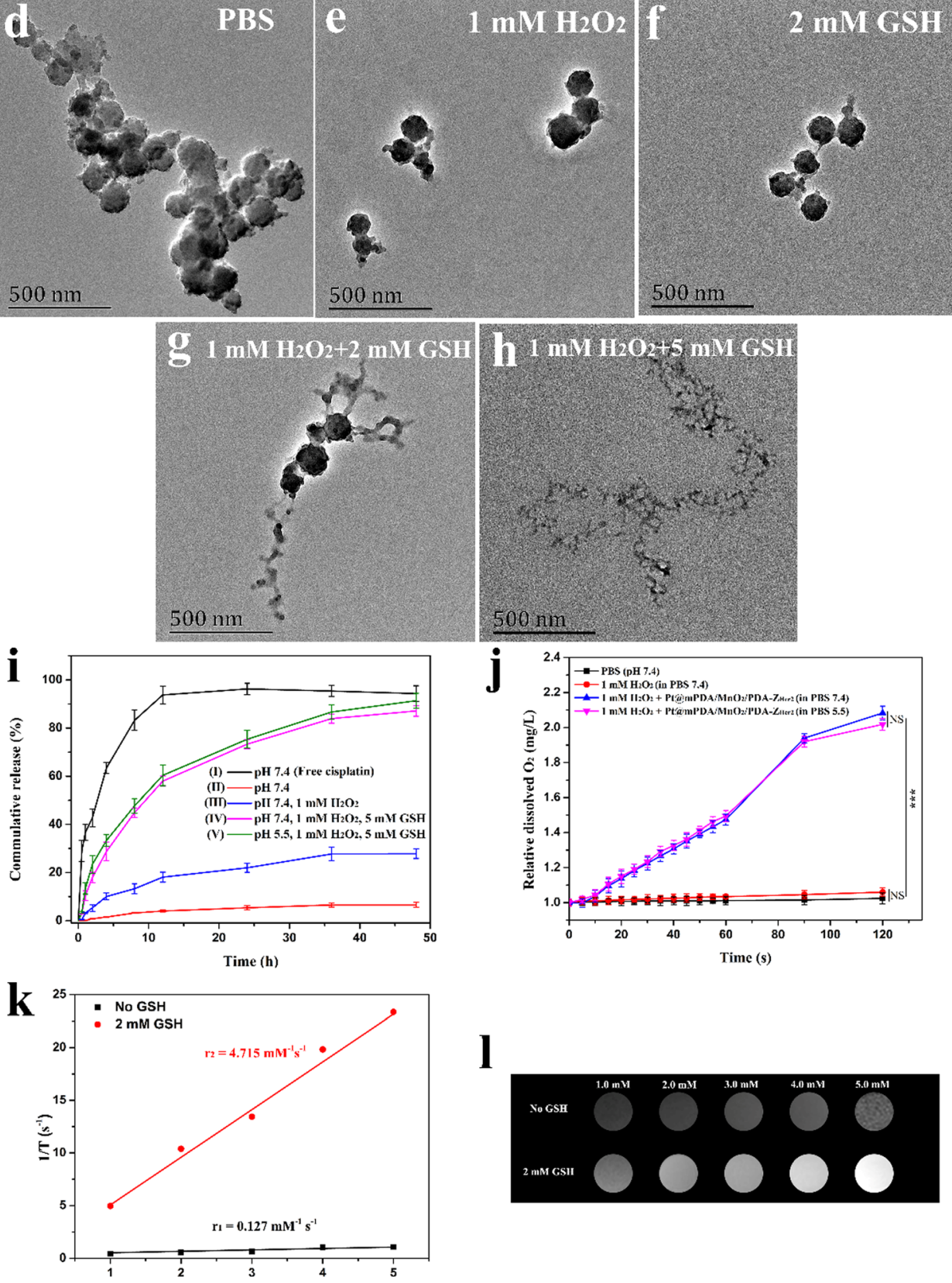

I

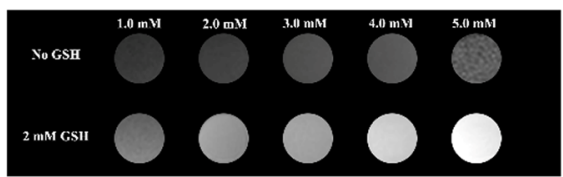



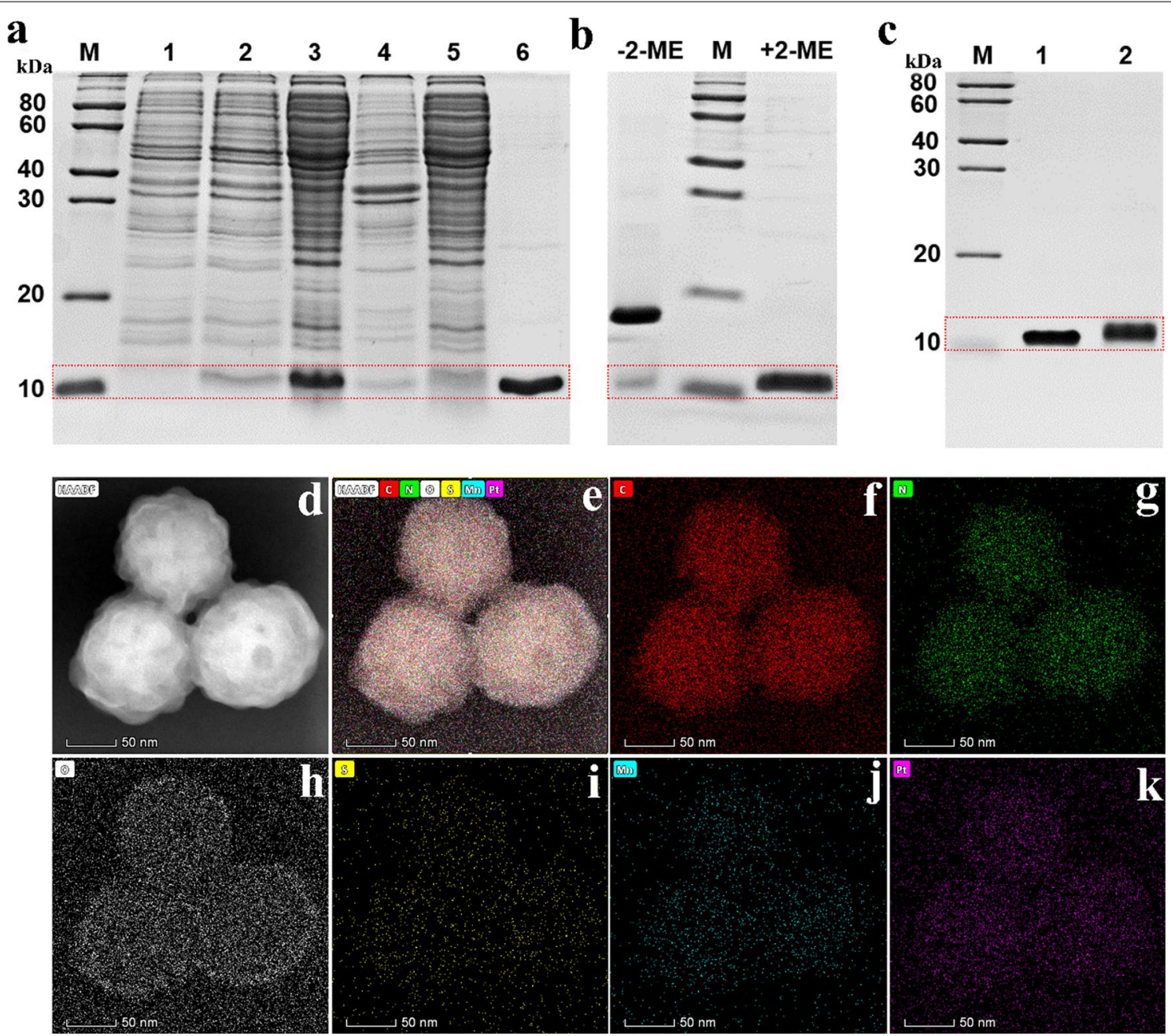

Fig. 2 a SDS-PAGE of samples collected during $Z_{\text {Her2 }}$ preparation. M, protein marker; lane 1, total protein of uninduced cells; lane 2, total protein of induced cells; lane 3, soluble protein of induced cells; lane 4, insoluble protein of induced cells; lane 5, flow-through fractions after binding to NiNTA resin; lane 6, protein purified by Ni-NTA affinity chromatography. $\mathbf{b}$ SDS-PAGE of the purified $Z_{\text {Her2 }}$ affibody in the presence or absence of 2-ME. c SDS-PAGE characterization of $Z_{\text {Her2 }}$ labelled with 6-FAM. M, protein marker; lane 1, unlabelled $Z_{\text {Her2 }}$; lane 2, 6-FAM-labelled $Z_{\text {Her2. }}$. d HAADF-STEM

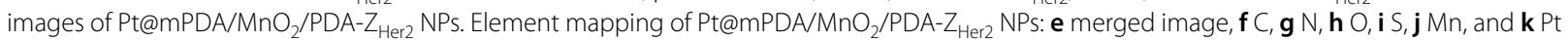

(Fig. 2a, lane 4) fractions revealed that the recombinant protein was mainly expressed as a soluble protein. After binding to Ni-NTA affinity resin, the amount of recombinant protein in the flow-through fractions was remarkably reduced (Fig. 2a, lane 5), suggesting high purification efficiency. The purified $Z_{\mathrm{Her} 2}$ protein was visualized as a single protein band on an SDS-PAGE gel, and the purity was calculated to be more than $95 \%$ according to scanning densitometry of the electrophoretic bands (Fig. 2a, lane 6). Approximately $30-40 \mathrm{mg}$ of protein was obtained from $E$. coli cells in $1 \mathrm{~L}$ of culture.

The affinity of the dimeric form affibody for its target is usually higher than that of the monomeric form [47]. So, the $\mathrm{Z}_{\mathrm{Her} 2}$ affibody was dimerized upon the addition of a cysteine residue at the $\mathrm{C}$-terminus. As expected, the molecular weight of $\mathrm{Z}_{\mathrm{Her} 2}$ under natural conditions (Fig. 2b, in the absence of 2-ME) was approximately double than that of $Z_{\mathrm{Her} 2}$ under reductive conditions (Fig. $2 \mathrm{~b}$, in the presence of $2-\mathrm{ME})$, indicating that $\mathrm{Z}_{\mathrm{Her} 2}$ forms disulfide bonds and dimers under natural conditions.

A slight increase in molecular weight was observed after $\mathrm{Z}_{\mathrm{Her} 2}$ was labelled with the fluorescent agent 6-Carboxfluorescein (6-FAM) (Fig. 2c), with a labelling efficiency was approximately $100 \%$. This label allowed for visual evaluation of the binding capacity between FAM$\mathrm{Z}_{\mathrm{Her} 2}$ and Her2-positive cells.

Finally, the $\mathrm{Z}_{\mathrm{Her} 2}$ affibody was coupled with $\mathrm{Pt} @$ $\mathrm{mPDA} / \mathrm{MnO}_{2} / \mathrm{PDA} \mathrm{NPs}$ via a Michael addition/Schiff 
(See figure on next page.)

Fig. 3 a CLSM images of SKOV-3 cells after $2 \mathrm{~h}$ incubation with Cy5.5@mPDA/MnO $2 / P D A N P s$ and Cy5.5@mPDA/MnO $2 / P D A-Z_{\text {Her2 }}$ NPs and after a 1 h pre-treatment with or without $Z_{\text {Her2 }}$. b Flow cytometry data for untreated SKOV-3 cells, SKOV-3 cells incubated for 4 h with Cy5.5@mPDA/MnO $/$ PDA NPs or Cy5.5@mPDA/MnO $/ 2 / P D A-Z_{\text {Her2 }}$ NPs, and cells pre-incubated with $Z_{\text {Her } 2}$ for 1 h before being exposed to Cy5.5@mPDA/MnO $/$ PDA-Z NPs for $4 \mathrm{~h}$, and fluorescence intensity quantified. c MTT viability results for SKOV-3 cells after incubation with free cisplatin (Pt), Pt@mPDA/MnO $2 /$ PDA NPs, and Pt@mPDA/MnO $/ 2 / P D A-Z_{\text {Her } 2}$ NPs for 24 h. d Fluorescence images of calcein-AM/PI co-stained SKOV-3 cells after different treatments (dose of cisplatin: $48 \mu \mathrm{g} / \mathrm{mL}$ ). e Intracellular ROS levels in SKOV-3 cells after treatment with different formulations

base reaction by conjugating the amino group to the oxidized quinone form of the catechol groups under weak alkaline conditions. The mean hydrodynamic size of NPs increased slightly from 185 to $201 \mathrm{~nm}$ after $\mathrm{Z}_{\mathrm{Her} 2}$ affibody conjugation (Additional file 1: Fig. S5a). Both NPs exhibited high colloidal stability and could be dispersed in PBS without aggregation over $24 \mathrm{~h}$ (Additional file 1: Fig. S5b). The elemental mapping images (Fig. 2d-k) of mPDA/ $\mathrm{MnO}_{2} / \mathrm{PDA}-\mathrm{Z}_{\mathrm{Her} 2} \mathrm{NPs}$ showed a homogeneous distribution of $\mathrm{C}, \mathrm{N}, \mathrm{O}, \mathrm{S}, \mathrm{Mn}$, and $\mathrm{Pt}$, further confirming the successful loading of cisplatin and coupling of $\mathrm{Z}_{\mathrm{Her} 2}$. In addition, the $Z_{\mathrm{Her} 2}$ content was approximately $0.8 \mathrm{mg} / \mathrm{g}$ according to ICP-AES quantitation of the $Z_{\mathrm{Her} 2}$-specific S element.

\section{Her2-positive cell-specific binding and cytotoxicity assay}

Flow cytometry (FCM) and confocal laser scanning microscopy (CLSM) (Additional file 1: Fig. S6a-c) showed a concentration-dependent increase in fluorescence for a human ovarian cancer cell line (SKOV-3) after incubation with FITC-labelled anti-Her2 antibodies, while negligible FITC fluorescence was visible in a breast cancer cell line (MCF-7). This confirmed that SKOV-3 cells are Her2-positive, while MCF-7 cells are Her2-negative, which is consistent with previous results [48]. The binding activity of FAM- $\mathrm{Z}_{\mathrm{Her} 2}$ with Her2-negative MCF-7 cells and Her2-positive SKOV-3 cells was examined by CLSM. As shown in Additional file 1: Fig. S7a, FAM-Z specifically binds to SKOV-3 cells, while negligible FAM$\mathrm{Z}_{\mathrm{Her} 2}$ binding to MCF-7 cells was seen, indicating that these affibodies bind specifically to Her2-positive cancer cells. This Her2-specific binding activity was further confirmed by FCM, as strong FAM fluorescence was visible in SKOV-3 cells, while the binding was significantly reduced after pre-incubation with free $\mathrm{Z}_{\mathrm{Her} 2}$ (Additional file 1: Fig. S7b).

FCM analysis was performed to evaluate the affinity of affibody monomers and dimers to Her2 receptors by measuring the FAM fluorescence intensity. As shown in Additional file 1: Fig. S8a, the binding rates of the dimeric Her2 affibody were $58.4 \%$, compared to $33.8 \%$ for the monomer Her2 affibody at the same molar concentration. This confirms that the affinity of the dimeric Her2 affibody was higher than that of the monomeric Her2 affibody for Her2 receptors.
To determine whether $Z_{\mathrm{Her} 2}$ could enhance the internalization of NPs into Her2-overexpressing tumor cells, the uptake of Cy5.5-labelled mPDA/ $\mathrm{MnO}_{2} / \mathrm{PDA}$ (Cy5.5@mPDA $/ \mathrm{MnO}_{2} / \mathrm{PDA}$ ) and $\mathrm{mPDA} / \mathrm{MnO}_{2} / \mathrm{PDA}$ $\mathrm{Z}_{\mathrm{Her} 2}\left(\mathrm{Cy} 5.5 @ \mathrm{mPDA} / \mathrm{MnO}_{2} / \mathrm{PDA}-\mathrm{Z}_{\mathrm{Her}}\right.$ ) NPs by SKOV-3 cells was measured using CLSM and quantified via a FCM assay. Minimal intracellular red fluorescence was observed in SKOV-3 cells after treatment with Cy5.5@ $\mathrm{mPDA} / \mathrm{MnO}_{2} / \mathrm{PDA} \mathrm{NPs}$ (Fig. 3a). In striking contrast, strong Cy5.5 (red) fluorescence was visible in SKOV-3 cells after incubation with Cy5.5@mPDA/ $\mathrm{MnO}_{2} / \mathrm{PDA}$ $\mathrm{Z}_{\mathrm{Her} 2}$ NPs. A blocking experiment was carried out by pre-incubating SKOV-3 cells with free $Z_{\mathrm{Her} 2}(20 \mu \mathrm{g} / \mathrm{mL})$ to further explore the mechanism of endocytosis. CLSM images showed an attenuated fluorescence signal inside pre-incubated SKOV-3 cells, indicating that the occupation of Her2 receptors resulted in reduced endocytosis and therefore failed to bind the NP-conjugated $Z_{H e r 2}$. Similarly, the FCM data showed that the uptake of cellular NPs significantly increased after conjugating $\mathrm{Z}_{\mathrm{Her} 2}$ to Cy5.5@mPDA/ $\mathrm{MnO}_{2} / \mathrm{PDA} \mathrm{NPs}$; however, the cellular uptake was significantly reduced after pre-incubation of SKOV-3 cells with free $Z_{\mathrm{Her} 2}$ (Fig. 3b). Collectively, these results confirm that the $Z_{\mathrm{Her} 2}$ affibody can enhance the internalization of NPs into Her2-positive cancer cells due to the specific affinity between the $\mathrm{Z}_{\mathrm{Her} 2}$ affibody and the Her2 receptor.

The cytocompatibility of drug-free $\mathrm{mPDA} / \mathrm{MnO}_{2} /$ PDA- $Z_{\text {Her2 }}$ NPs with human umbilical vein endothelial cells (HUVECs) was assessed using the MTT assay. As shown in Additional file 1: Fig. S8b, negligible toxicity to non-cancerous cells was observed, even when the concentration of $\mathrm{mPDA} / \mathrm{MnO}_{2} / \mathrm{PDA}-\mathrm{Z}_{\mathrm{Her} 2} \mathrm{NPs}$ reached $250 \mu \mathrm{g} / \mathrm{mL}$ ( $>90 \%$ viability), thus demonstrating the good cytocompatibility of the carrier materials.

All cisplatin-containing formulations exhibited dosedependent cytotoxicity to SKOV-3 cells (Fig. 3c). The half maximal inhibitory concentrations $\left(\mathrm{IC}_{50}\right)$ of free cisplatin, Pt@mPDA/ $\mathrm{MnO}_{2} / \mathrm{PDA} \mathrm{NPs}$, and Pt@mPDA/ $\mathrm{MnO}_{2} / \mathrm{PDA}-\mathrm{Z}_{\mathrm{Her} 2}$ NPs for SKOV-3 cells were $9.79 \pm 0.8$ $\mu \mathrm{g} / \mathrm{mL}, 3.18 \pm 0.3 \mu \mathrm{g} / \mathrm{mL}$, and $2.56 \pm 0.1 \mu \mathrm{g} / \mathrm{mL}$, respectively. In contrast to free cisplatin, the Pt@mPDA/ $\mathrm{MnO}_{2} /$ PDA NPs exhibited more potent toxicity to cells over the entire cisplatin dose range $(0.6-48 \mu \mathrm{g} / \mathrm{mL})$, which can be ascribed to more efficient cellular uptake of NPs. More 

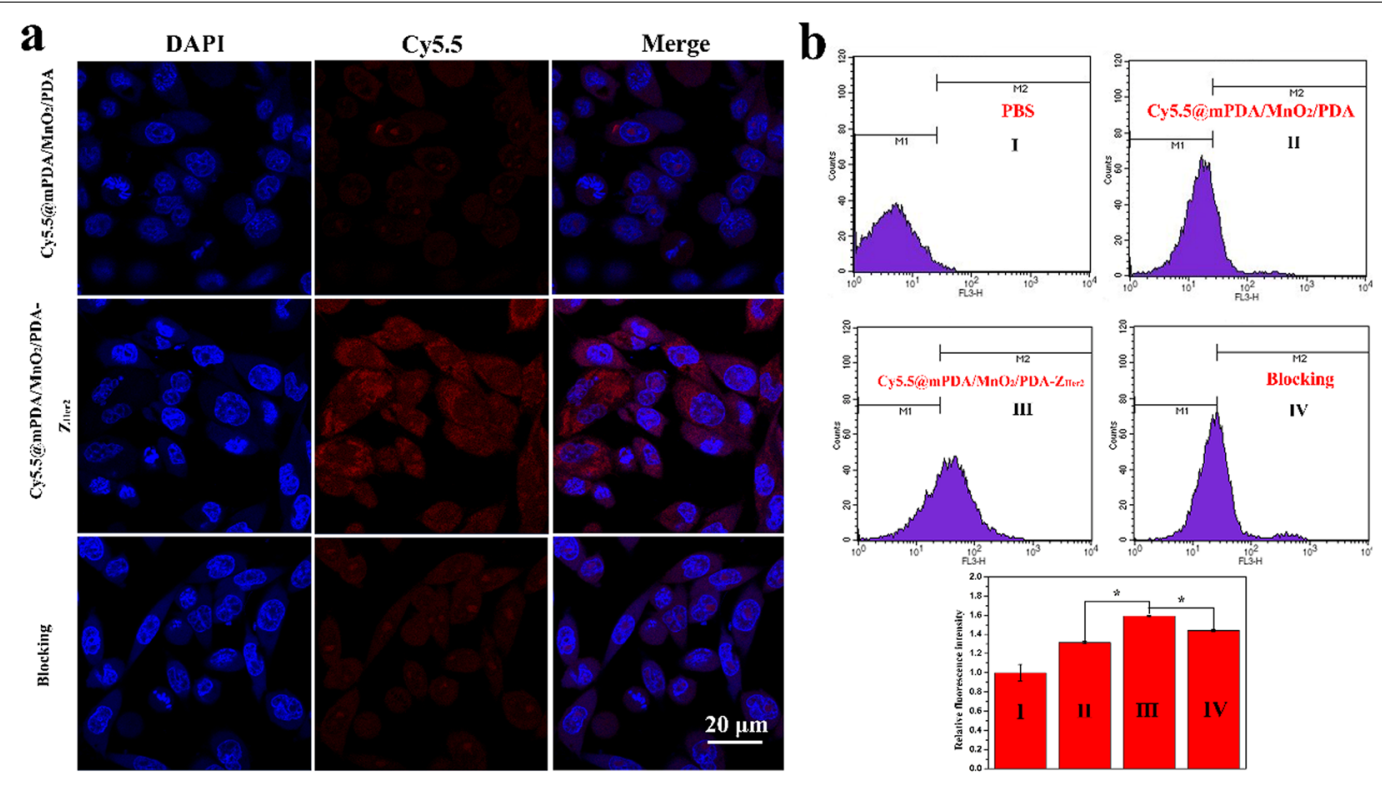

c

d
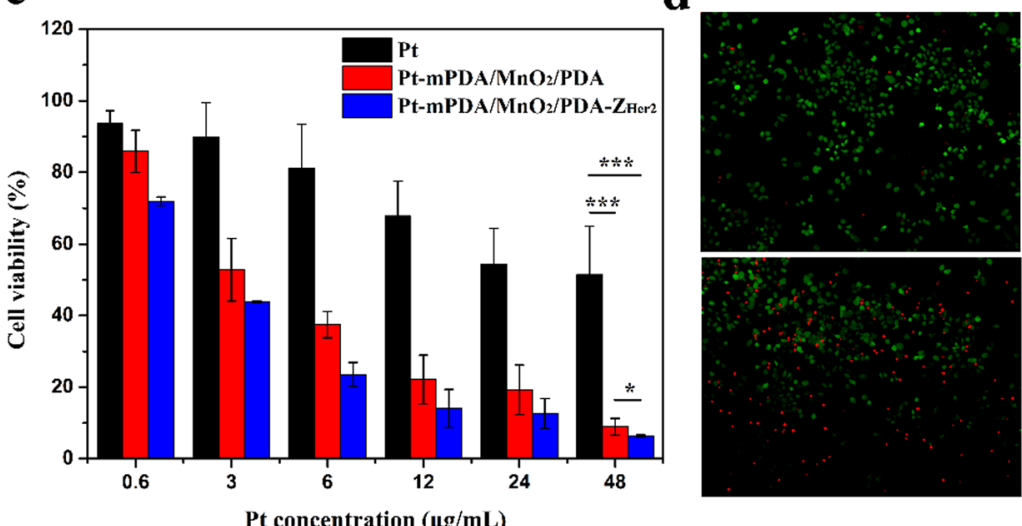

$\mathrm{Pt} @ \mathrm{mPDA} / \mathrm{MnO}_{2} / \mathrm{PD}$
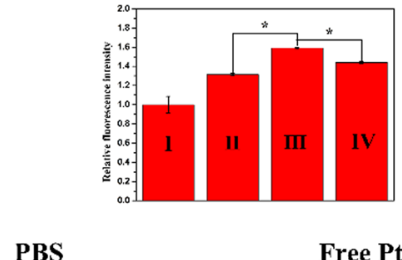

e

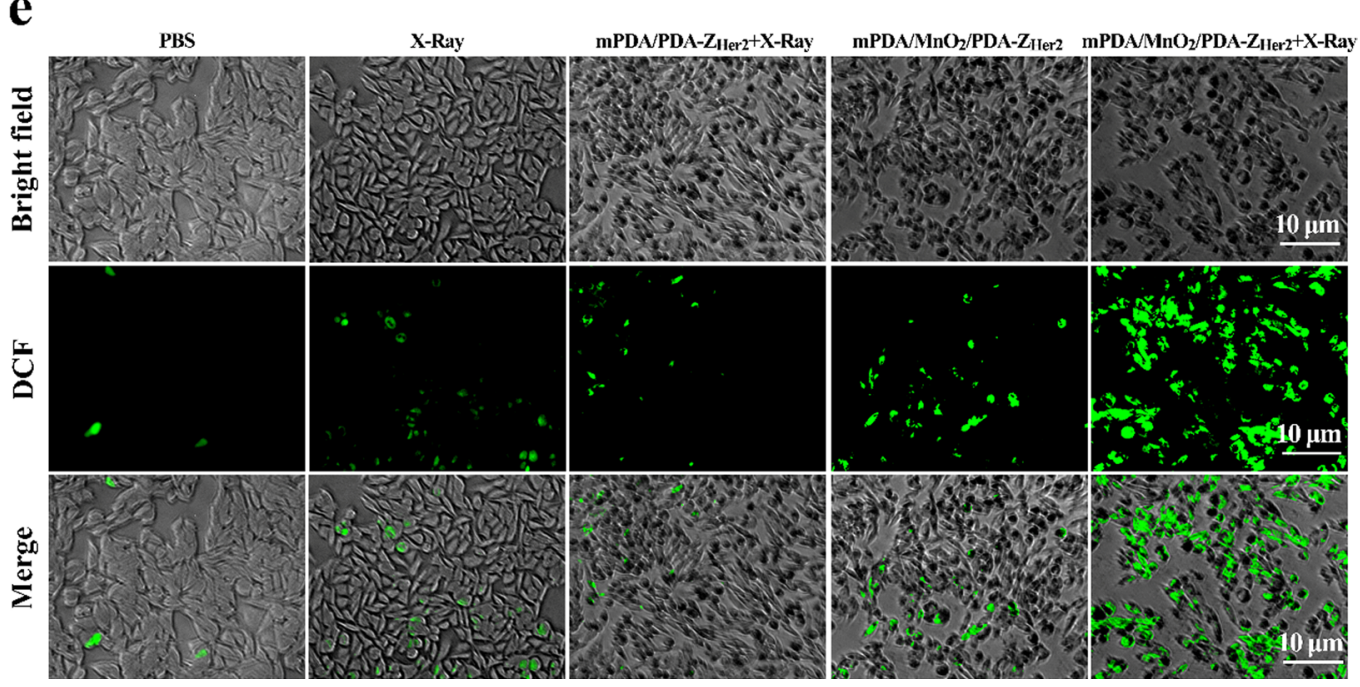


encouragingly, the conjugation of $\mathrm{Z}_{\mathrm{Her} 2}$ to Pt@mPDA/ $\mathrm{MnO}_{2} / \mathrm{PDA}$ NPs further improved the cytotoxicity of the NPs because of more efficient internalization mediated by the targeted affinity for $Z_{\mathrm{Her} 2}$ on the NPs to Her2 receptors on SKOV-3 cells.

Calcein-AM/PI double staining was performed to evaluate the degree of apoptosis of the cells. The optimal degree of cell apoptosis was observed upon treatment with Pt@mPDA $/ \mathrm{MnO}_{2} / \mathrm{PDA}-\mathrm{Z}_{\mathrm{Her} 2} \mathrm{NPs}$ (Fig. 3d), which is consistent with the MTT results.

Since $\mathrm{O}_{2}$ is the ROS-generating resource induced by $\mathrm{X}$-ray treatment, we next evaluated the effect of $\mathrm{MnO}_{2}$-containing NPs on the intracellular oxidative stress levels. As shown in Fig. 3e, compared to X-ray treatment alone, treatment with $\mathrm{MnO}_{2}$-free mPDA/ PDA- $Z_{\mathrm{Her} 2} \mathrm{NPs}$ combined with X-ray did not increase the intracellular ROS levels, as low DCF fluorescence was observed in cells receiving X-ray treatment with or without mPDA/PDA- $Z_{\mathrm{Her} 2}$ NPs. The intracellular oxidative stress levels of SKOV-3 cells improved after treatment with mPDA $/ \mathrm{MnO}_{2} / \mathrm{PDA}-\mathrm{Z}_{\mathrm{Her} 2} \mathrm{NPs}$ alone, which can be ascribed to their ability of $\mathrm{MnO}_{2}$ to produce $\mathrm{HO}$. (one ROS species) [14, 15]. In stark contrast, cells receiving $\mathrm{mPDA} / \mathrm{MnO}_{2} / \mathrm{PDA}-\mathrm{Z}_{\mathrm{Her} 2} \mathrm{NPs}$ and $\mathrm{X}$-ray combined treatment largely increased the intracellular ROS levels compared with cells receiving $\mathrm{MnO}_{2}$-free mPDA/PDA$\mathrm{Z}_{\mathrm{Her} 2} \mathrm{NPs}+\mathrm{X}$-ray treatment. This finding indicates that treatment with $\mathrm{MnO}_{2}$-containing NPs can facilitate ROS generation induced by ionizing radiation, confirming that these NPs have the capacity to increase radiosensitivity.

\section{Hemolysis assay in vitro}

A hemolysis assay was performed to determine the pharmacological safety of the NPs. No morphological changes and no significant lysis were observed after RBCs were incubated with Pt@mPDA/ $\mathrm{MnO}_{2} / \mathrm{PDA}$ NPs or Pt@ mPDA $/ \mathrm{MnO}_{2} / \mathrm{PDA}-\mathrm{Z}_{\mathrm{Her} 2} \mathrm{NPs}$ (Additional file 1: Fig. S9a, b). Both Pt@mPDA/MnO $/ 2$ PDA NPs and Pt@mPDA/ $\mathrm{MnO}_{2} / \mathrm{PDA}-\mathrm{Z}_{\mathrm{Her} 2}$ NPs had low hemolytic activity with only $\sim 4.4 \%$ and $\sim 4.7 \%$ RBC lysis, respectively (Additional file 1: Fig. S9c). The results indicate that both Pt@mPDA/ $\mathrm{MnO}_{2} / \mathrm{PDA} \mathrm{NPs}$ and Pt@mPDA $/ \mathrm{MnO}_{2} / \mathrm{PDA}-\mathrm{Z}_{\mathrm{Her} 2} \mathrm{NPs}$ are blood compatible biomaterials.

\section{Tumor targeting profiles in vivo}

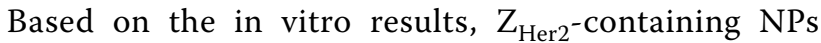
were expected to target Her2-overexpressing tumor in vivo. The TME-activated MRI ability of NPs was first investigated in the SKOV-3 tumor-bearing mouse model. The $\mathrm{T}_{1}$-weighted MRI signal in the tumors increased gradually over time, while negligible MRI signal enhancement was observed in the muscles
(Fig. 4a and b). This can be attributed to the reduction of the $\mathrm{MnO}_{2}$ layer to the MRI agent $\mathrm{Mn}^{2+}$ by the high levels of GSH in the TME $[15,49]$, which makes the $\mathrm{MnO}_{2}$-containing NPs particularly attractive for tumor-specific imaging applications. Tumor accumulation of Pt@mPDA/ $\mathrm{MnO}_{2} / \mathrm{PDA}$ and Pt@mPDA/ $\mathrm{MnO}_{2} / \mathrm{PDA}-\mathrm{Z}_{\mathrm{Her} 2} \mathrm{NPs}$ in SKOV-3 tumor-bearing mice at different times after intravenous injection was evaluated by tracking the MRI signal. The MRI signal was observed at the tumor site at $1 \mathrm{~h}$ post-injection of $\mathrm{Pt} @ \mathrm{mPDA} / \mathrm{MnO}_{2} / \mathrm{PDA}-\mathrm{Z}_{\mathrm{Her} 2} \mathrm{NPs}$, and the intensity increased gradually over time, indicating tumor-specific accumulation of these NPs (Fig. 4c). In contrast, decreased tumor accumulation of Pt@mPDA/ $/ \mathrm{MnO}_{2} /$ PDA NPs was observed as the signal of the Pt@mPDA/ $\mathrm{MnO}_{2} / \mathrm{PDA}-\mathrm{Z}_{\mathrm{Her} 2} \mathrm{NPs}$ was significantly stronger than that of Pt@mPDA $/ \mathrm{MnO}_{2} / \mathrm{PDA} \mathrm{NPs}(\mathrm{p}<0.05)$ at $6 \mathrm{~h}$ (Fig. 4d). The biodistribution of free cisplatin, Pt@ mPDA $/ \mathrm{MnO}_{2} / \mathrm{PDA}$, and Pt@mPDA $/ \mathrm{MnO}_{2} / \mathrm{PDA}-\mathrm{Z}_{\mathrm{Her} 2}$ NPs in SKOV-3 tumors was determined by quantifying the Pt content using ICP-AES at $12 \mathrm{~h}$ post-injection (Additional file 1: Fig. S10). The Pt content in the tumors of mice treated with Pt@mPDA $/ \mathrm{MnO}_{2} / \mathrm{PDA}$ $\mathrm{Z}_{\mathrm{Her} 2}$ NPs was approximately 3.5 -fold and two fold higher than that in mice treated with free cisplatin and Pt@mPDA $/ \mathrm{MnO}_{2} / \mathrm{PDA}$ NPs, respectively. The results reflect the more tumor retention of cisplatin-loaded NPs and tumor-targeting ability of the $\mathrm{Z}_{\mathrm{Her} 2}$ affibody.

Immunofluorescence and bio-TEM assays were performed to further evaluate the tumor-targeting ability of Cy5.5@mPDA/ $\mathrm{MnO}_{2} / \mathrm{PDA}-\mathrm{Z}_{\mathrm{Her} 2} \mathrm{NPs}$ at the histological level. Immunofluorescence staining showed that Cy5.5 fluorescence (representing Cy5.5@mPDA/ $\mathrm{MnO}_{2} /$ PDA NPs) was mainly restricted to the tumor peripheral tissue (Fig. 5a and c (I)), suggesting poor penetration of the NPs into the TME. It was very encouraging to see that in the presence of $Z_{\mathrm{Her} 2}$, the NPs overcame these biological barriers and penetrated deeply into the tumor tissue. As shown in Fig. 5b and c (II), strong red fluorescence was observed throughout the tumor, which co-localized with green fluorescence (representing Her2). These results confirm the efficient tumor homing and penetration of Cy5.5@mPDA/ $\mathrm{MnO}_{2} / \mathrm{PDA}$ $\mathrm{Z}_{\mathrm{Her} 2} \mathrm{NPs}$, which is afforded by $\mathrm{Z}_{\mathrm{Her} 2}$.

This effect was also confirmed by bio-TEM imaging (Fig. 6) of tumor tissue. Greater amounts of Cy5.5@ $\mathrm{mPDA} / \mathrm{MnO}_{2} / \mathrm{PDA}-\mathrm{Z}_{\mathrm{Her}}$ NPs were present within the cytoplasm, with little $\mathrm{Cy} 5.5 @ \mathrm{mPDA} / \mathrm{MnO}_{2} / \mathrm{PDA}$ NPs being observed in the tumor tissue. This superior tumor penetration and targeting capabilities are crucial for enhancing therapeutic efficacy. All these findings suggest that $\mathrm{Z}_{\mathrm{Her} 2}$ modification combined with a TMEtriggered off-to-on diagnostic agent make Pt@mPDA/ 


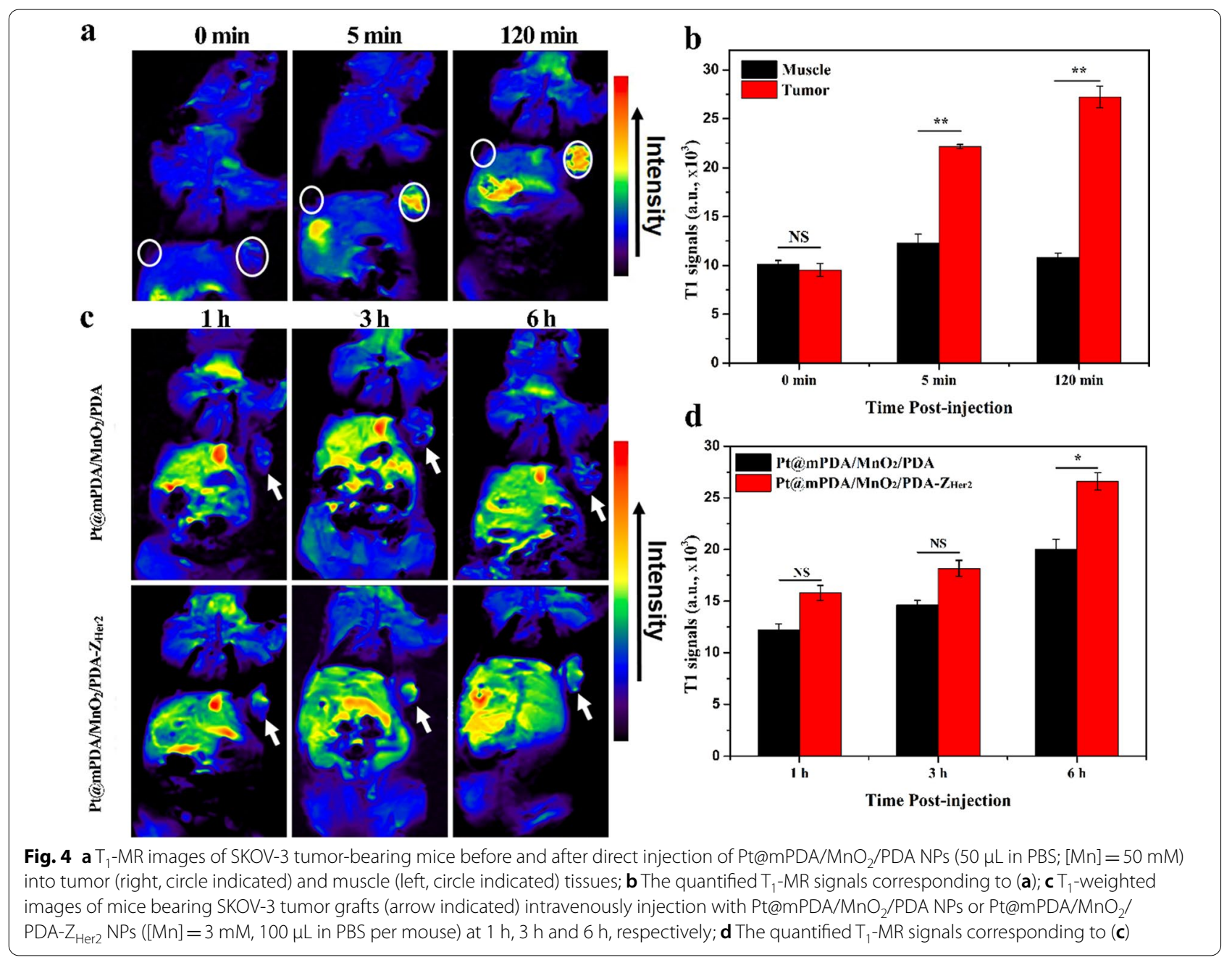

$\mathrm{MnO}_{2} / \mathrm{PDA}-\mathrm{Z}_{\mathrm{Her} 2}$ NPs particularly attractive for MRIguided tumor-targeting treatment.

\section{In vivo chemo-sensitized radiotherapy}

Encouraged by the tumor-targeting and penetration effects of $\mathrm{Z}_{\mathrm{Her} 2}$-functionalized NPs, the in vivo chemotherapeutic activities in SKOV-3 tumor-bearing mice were then assessed. In mice treated with PBS, the tumor volume increased steadily during the treatment period (Fig. 7a). Mice that were administered free cisplatin did not exhibit appreciable tumor suppression, probably due to insufficient accumulation of cisplatin in the tumors. In sharp contrast, mice that received $\mathrm{Pt} @ \mathrm{mPDA} / \mathrm{MnO}_{2} / \mathrm{PDA} \mathrm{NPs}$ showed inhibited tumor progression as a result of the improved tumor retention of cisplatin-containing NPs. As expected, with the guidance of the $\mathrm{Z}_{\mathrm{Her} 2}$ affibody, Pt@mPDA/ $\mathrm{MnO}_{2} /$ PDA- $\mathrm{Z}_{\mathrm{Her} 2}$ NPs achieved the most potent inhibition of tumor growth, and by the end of the treatment, these extracted tumors had the smallest volume and mass
(Fig. 7b and c), persuasively demonstrating the excellent targeted antitumor activity of Pt@mPDA/ $/ \mathrm{MnO}_{2} /$ PDA- $Z_{\text {Her2 }}$ NPs. Body weight was monitored every day, and no obvious difference was observed among all the treated groups (Fig. 7d).

A TUNEL assay was conducted to determine the levels of apoptosis in the tumor tissue. The largest number of green-colored cells (indicating the highest levels of apoptosis) were observed in tumors taken from mice receiving $\mathrm{Pt} @ \mathrm{mPDA} / \mathrm{MnO}_{2} / \mathrm{PDA}-\mathrm{Z}_{\mathrm{Her} 2} \mathrm{NPs}$ (Fig. 7e), indicating that these NPs had the most potent antitumor effects.

Based on the remarkable tumor inhibition effects of Pt@mPDA $/ \mathrm{MnO}_{2} / \mathrm{PDA}-\mathrm{Z}_{\mathrm{Her} 2} \mathrm{NPs}$, the combined chemo-radiation therapeutic efficacy with these NPs, especially the enhanced RT effect, by adopting $\mathrm{MnO}_{2}$ as a radiosensitizer for hypoxic tumors was next assessed. The treatment schedule for chemo-radiotherapy is illustrated in Fig. 8a. RT alone did not have any significant antitumor effects, possibly because of RT resistance caused by the hypoxic TME and a sharp growth in tumor size 
a

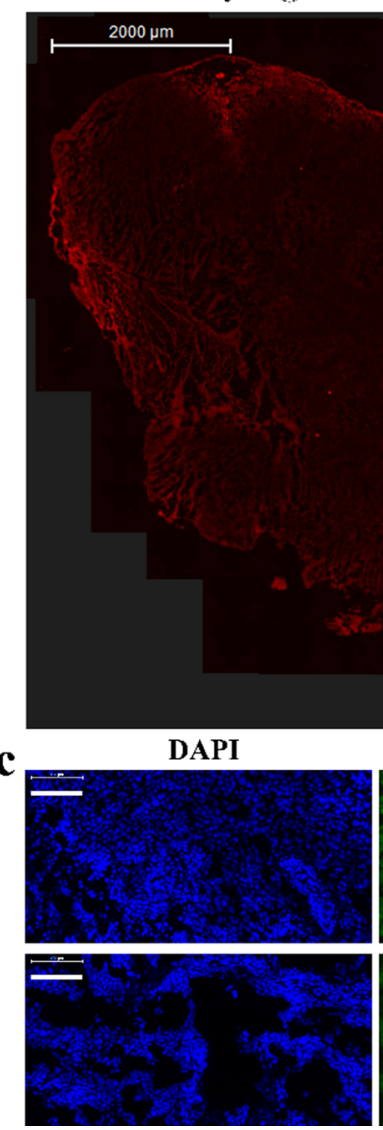
b $\quad$ Cy5.5@mPDA/MnO $2 / \mathrm{PDA}-Z_{\text {Her }}$

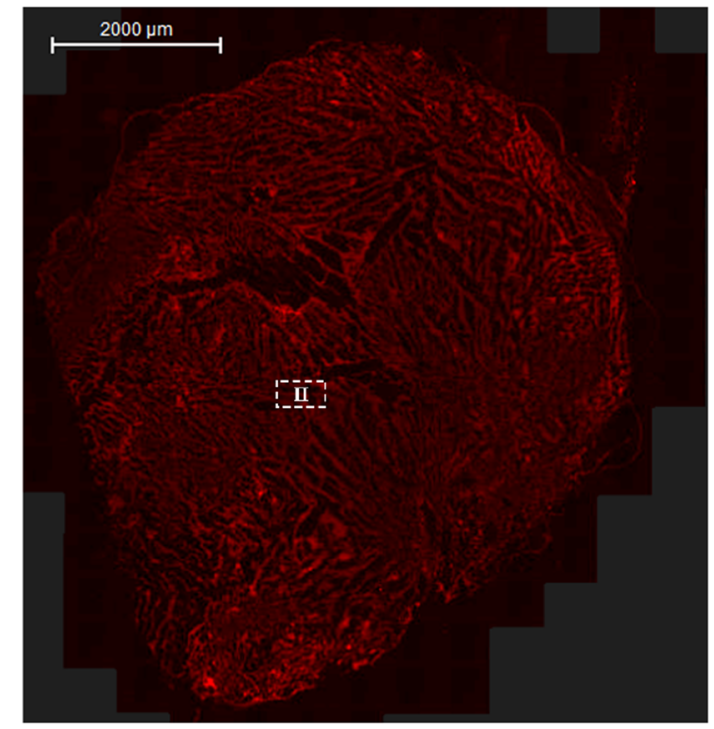

Cy5.5
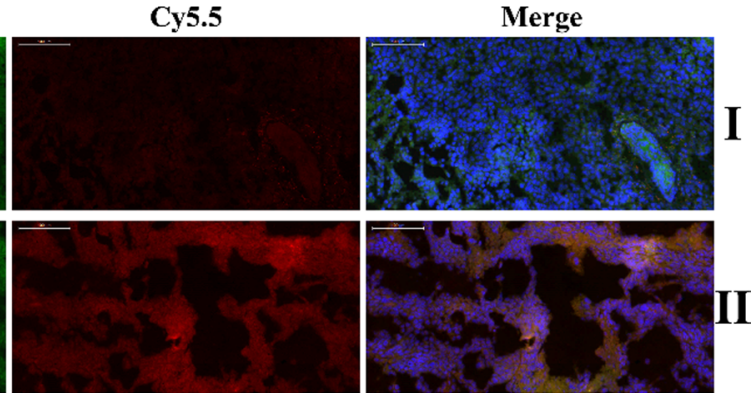

Fig. 5 Immunofluorescence assay of Cy5.5@mPDA/MnO $2 / P D A N P s$ and Cy5.5@mPDA/MnO $2 / P D A-Z_{\text {Her2 }}$ NPs in SKOV-3 tumor tissues. Mice bearing

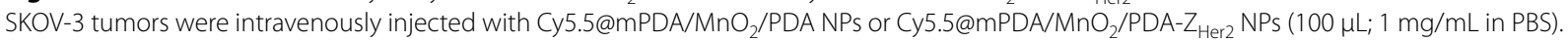
Tumors were collected and further studied by immunofluorescence assay after $12 \mathrm{~h}$ post-injection. a The immunofluorescence images of Cy5.5@ mPDA/MnO $2 /$ PDA NPs (red) in tumor tissues; b The immunofluorescence images of Cy5.5@mPDA/MnO $2 / P D A-Z_{\text {Her2 }}$ NPs (red) in tumor tissues; $\mathbf{c}$ Representative magnified immunofluorescence images corresponding to (a) and (b). Scale bar $=100 \mu \mathrm{m}$. The nuclei and Her2 were stained with DAPI (blue), anti-Her2 antibody (green), respectively

(Fig. 8b-d) was observed during the treatment period. Mice receiving Pt@mPDA/ $\mathrm{MnO}_{2} / \mathrm{PDA}-\mathrm{Z}_{\mathrm{Her} 2} \mathrm{NPs}$ and $\mathrm{X}$-ray irradiation exhibited the most profound inhibition of tumor growth, which was significantly more noticeable higher than that of the mice receiving $\mathrm{MnO}_{2}$-free Pt@mPDA/PDA- $Z_{\mathrm{Her} 2}$ NPs $+\mathrm{X}$-ray treatment $(\mathrm{p}<0.001)$. These results indicated successful sensitization to RT induced by $\mathrm{MnO}_{2}$. No obvious body weight changes were observed during any of the treatments for the duration of the experiment (Fig. 8e).

To better understand the mechanisms by which $\mathrm{MnO}_{2}$ sensitizes cells to RT, the HIF- $1 \alpha$ expression level was measured in tumor tissue extracted from each treatment group by an immunofluorescence assay. Compared with that in all $\mathrm{MnO}_{2}$-free formulation treatment groups, the tumor tissues from the mice treated with Pt@mPDA/ $\mathrm{MnO}_{2} / \mathrm{PDA}$ NPs showed a remarkable reduction in red fluorescence signal (HIF-1 $\alpha$ ) (Fig. 9). It indicated that TME in these mice was less hypoxic, which can be attributed to the decomposition of endogenous $\mathrm{H}_{2} \mathrm{O}_{2}$ to $\mathrm{O}_{2}$ by $\mathrm{MnO}_{2}$. Furthermore, with the targeted guiding of $\mathrm{Z}_{\mathrm{Her} 2}$ affibody, HIF- $1 \alpha$ expression was further reduced by treatment with Pt@mPDA/ $\mathrm{MnO}_{2} / \mathrm{PDA}-\mathrm{Z}_{\mathrm{Her} 2} \mathrm{NPs}$, confirming that the tumor-targeting ability of the $\mathrm{Z}_{\mathrm{Her} 2}$ affibody contributed to the sensitization to RT.

\section{Safety evaluation}

Evaluation of off-target toxicity is a prerequisite for in vivo use or clinical translation of novel therapeutic agents. Thus, the biocompatibility and biosafety of Pt@ $\mathrm{mPDA} / \mathrm{MnO}_{2} / \mathrm{PDA}-\mathrm{Z}_{\mathrm{Her} 2} \mathrm{NPs}$ were systematically evaluated by histology and serum biochemistry assays. H\&Estained images of major organs from all treatment mice showed no obvious tissue damage, compared with that 


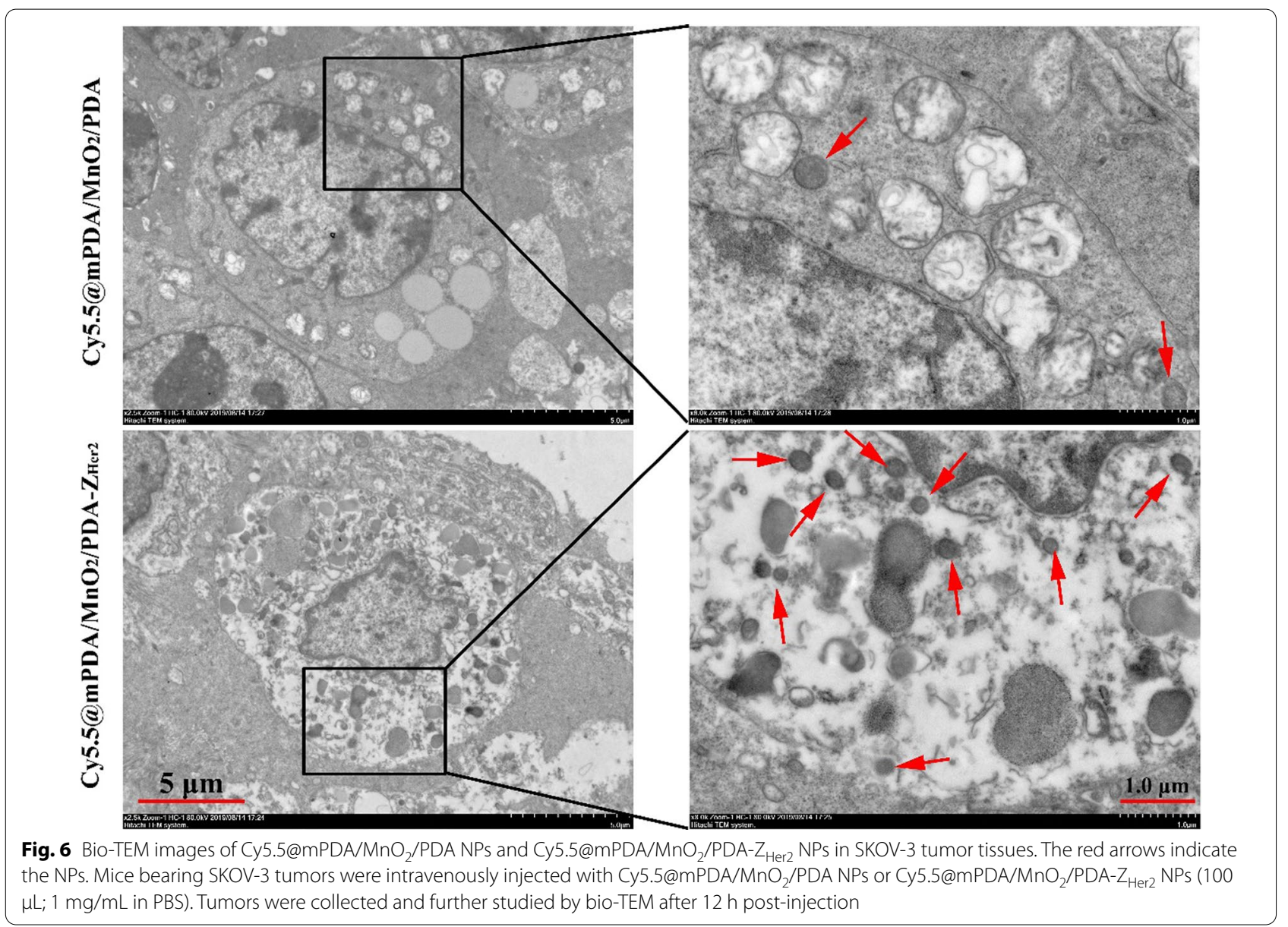

(See figure on next page.)

Fig. 7 In vivo chemotherapy efficacy of different formulations in mouse bearing SKOV-3 tumor grafts. When the volume of tumors reached about $50 \mathrm{~mm}^{3}$, mice were intravenously injected with cisplatin, Pt@mPDA/MnO $/ 2$ PDA NPs or Pt@mPDA/MnO $2 / P D A-Z_{\text {Her2 }}$ NPs (dose of cisplatin=2 mg/ $\mathrm{kg}$ ) every 2 days. Tumor-bearing mice intravenously injected with the same volume of PBS were used as control group. The tumor volume and body weight were measured every day. On the $14^{\text {th }}$ day after inoculation, all the tumor grafts were removed, weighed and analyzed by TUNEL staining. a SKOV-3 tumor growth curves of different groups after intravenously injection of the formulations. $\mathbf{b}$ The images of tumors isolated after treatment for 8 days. c Mean weights of the tumors isolated on day 14. d Body weight changes over the 8 days of the experiments. e TUNEL-stained images of tumor slices excised from each treatment group on day 14 . The nuclei of cells were visualized using DAPI (blue)

from the PBS group (Additional file 1: Fig. S11), suggesting that the drug, materials, or both combined did not cause any significant systemic toxicity. Similarly, the levels of serum biomarkers (ALT, AST, UREA, CREA, and UA) have no significant difference from those in the control group (Additional file 1: Fig. S12), possibly due to the relatively low side effects of clinical cisplatin and biomimetic PDA, as well as the short treatment period. Therefore, this biocompatible nano-theranostic agent exhibits promising potential for clinical translation.

Her2 is overexpressed in a variety of human cancers and is closely related to cell proliferation, differentiation, adhesion, migration, and anti-apoptosis, as well as poor prognosis and rapid recurrence of tumors [48]. Antibody-drug conjugates (ADCs, such as FDA-approved trastuzumab, pertuzumab, and T-DM1), which integrate Her2-specific targeting antibodies with highly cytotoxic small-molecule chemotherapeutic agents, possess the ability to selectively deliver highly potent cytotoxic drugs to tumor sites and have become a powerful cancer-targeting treatment approach. However, these ADCs can have a poor response in the TME and do not offer any diagnostic abilities, as well as being high cost, which limits their wider usage. In the present study, a Her2-targeting 

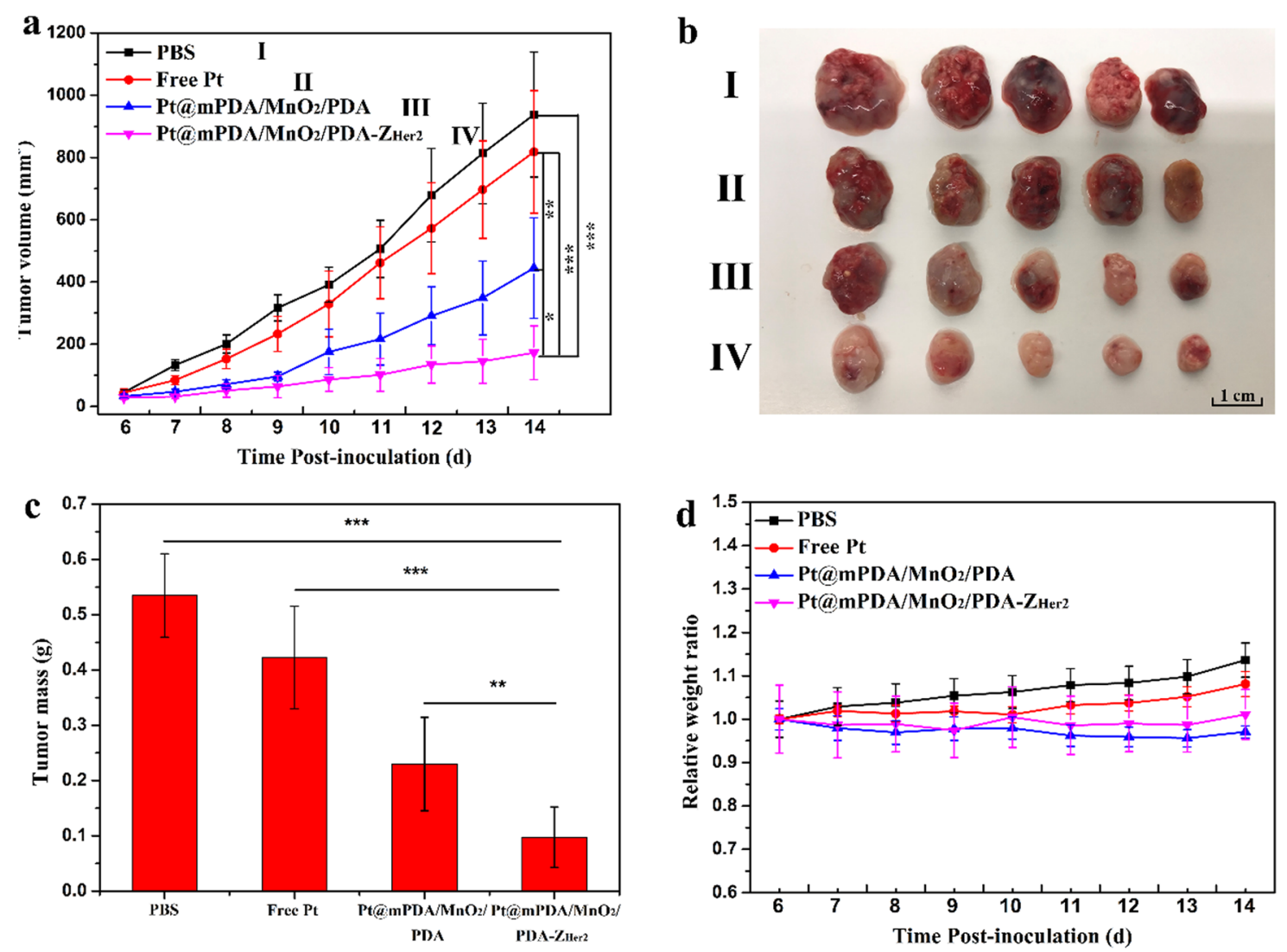

e

PBS

Free Pt

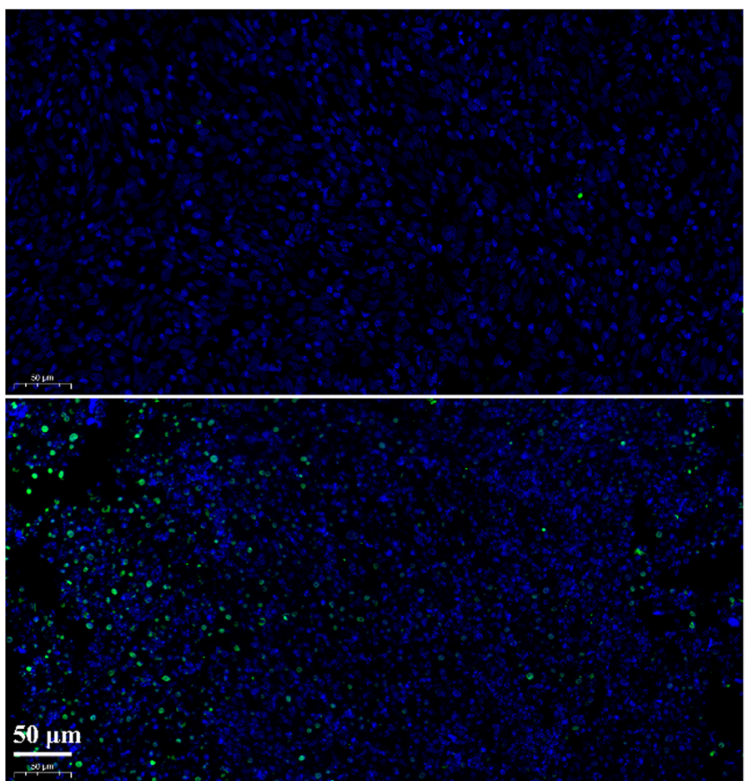

Pt@mPDA/MnO2/PDA

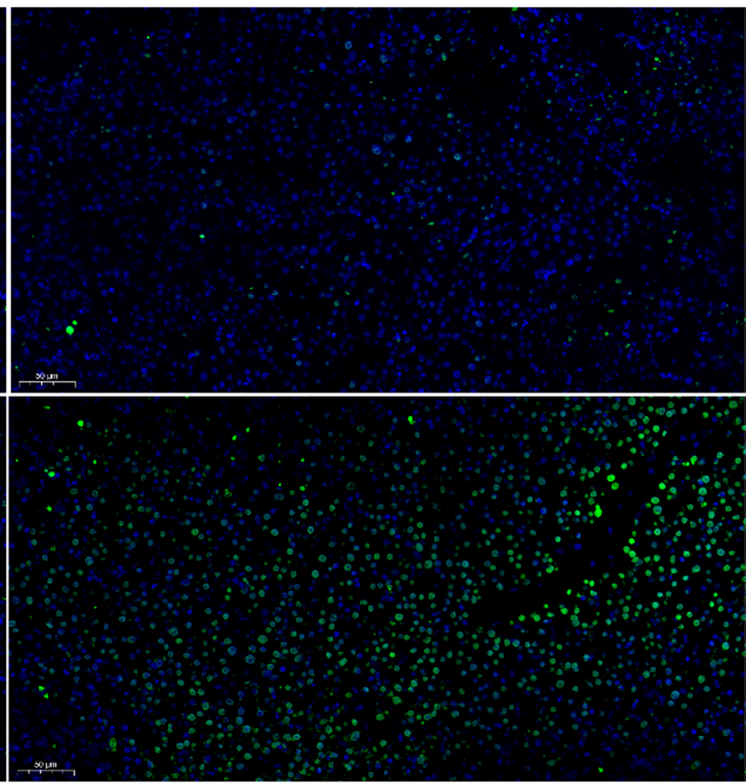

Pt@mPDA/MnO2/PDA-ZHer2 

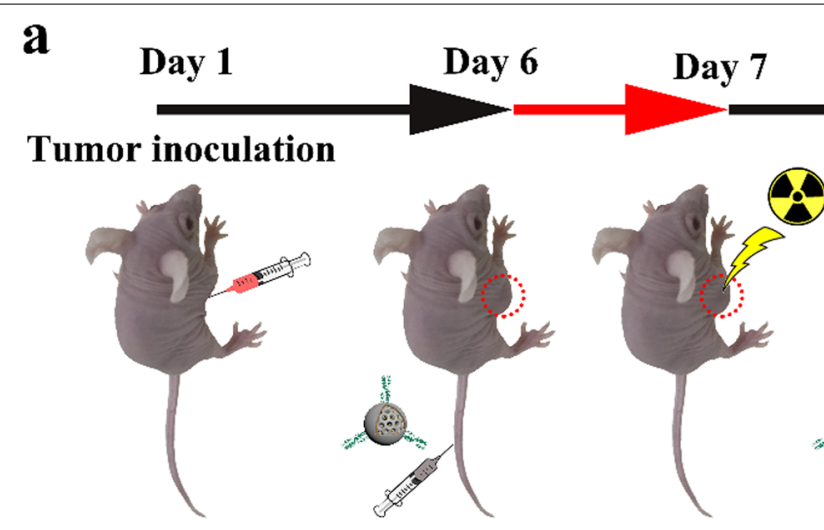

\section{Day 8, 10}

Day 11

Day 12, 14
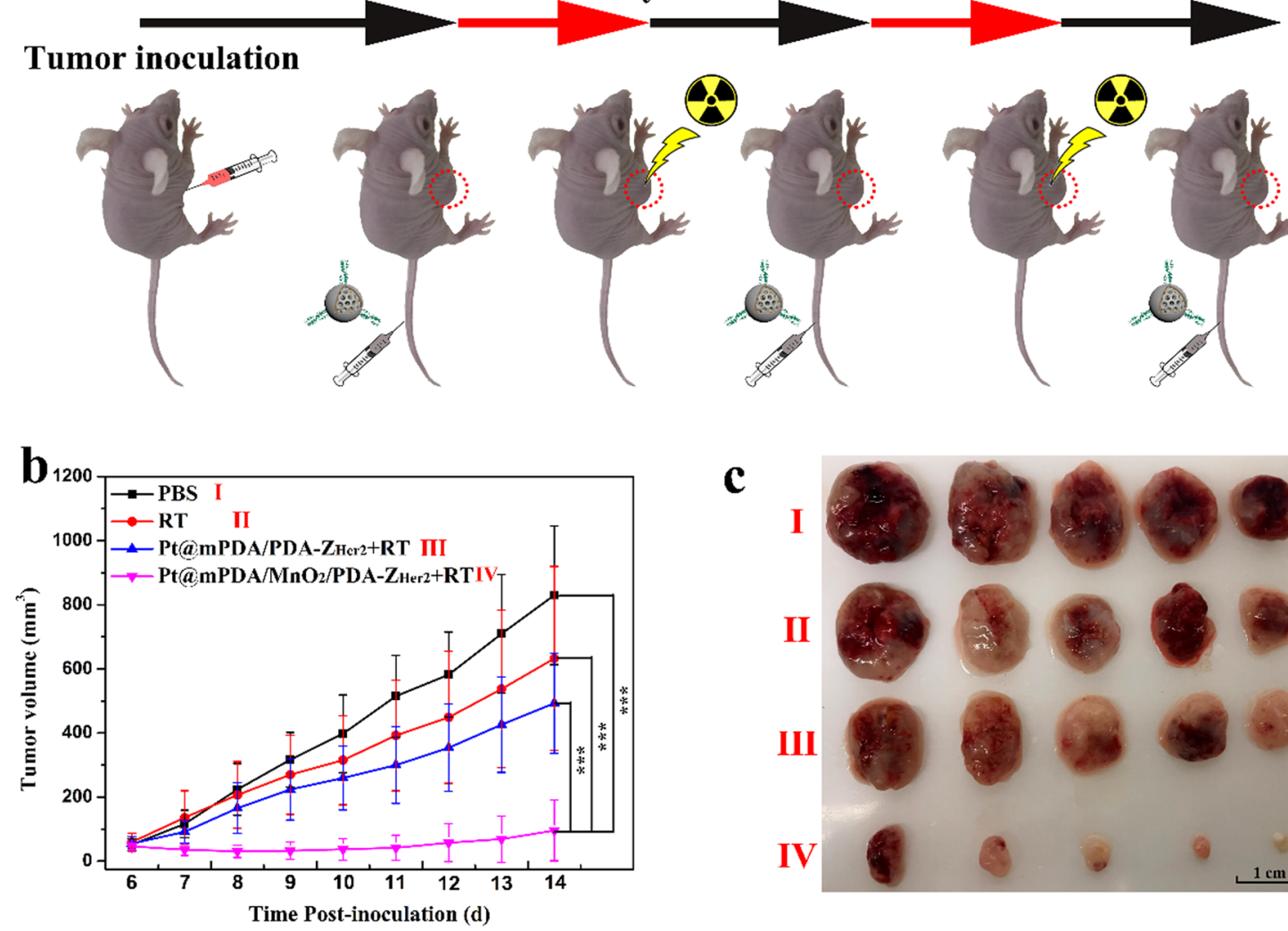

c
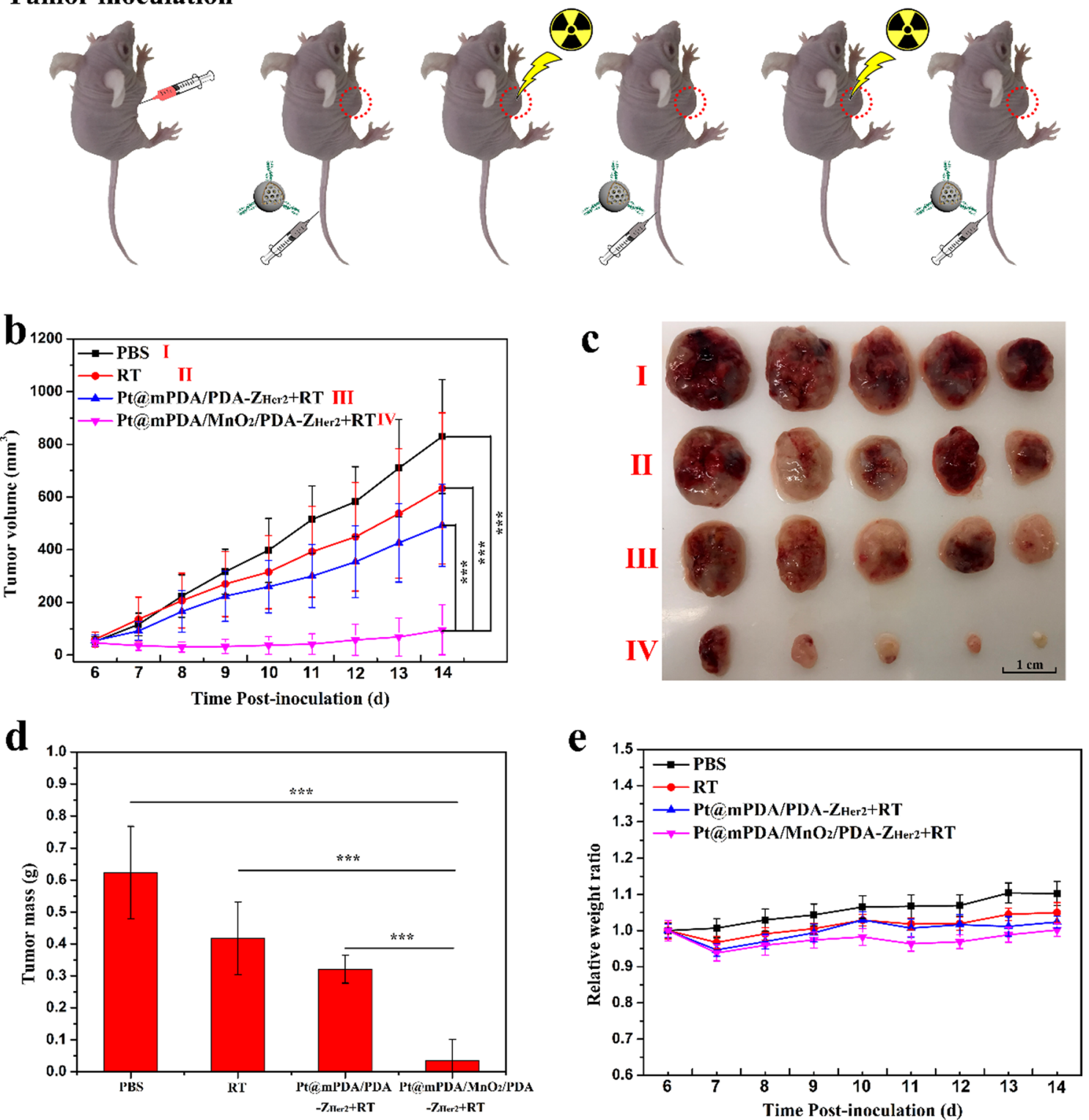

Fig. 8 In vivo chemo-radiation combined therapy efficacy of different formulations in mice bearing SKOV-3 tumor grafts. When the volume of tumors reached about $50 \mathrm{~mm}^{3}$, mice were intravenously injected with $\mathrm{MnO}_{2}$-free Pt@mPDA/PDA-Z $\mathrm{Z}_{\mathrm{Her} 2} \mathrm{NPs}$, Pt@mPDA/MnO 2 /PDA NPs or Pt@ $\mathrm{mPDA} / \mathrm{MnO}_{2} / \mathrm{PDA}-\mathrm{Z}_{\mathrm{Her} 2} \mathrm{NPs}$ every 2 days. Mice in control group were intravenously injected with same volume of PBS. Mice received an X-Ray radiation at a dose of $6 \mathrm{~Gy}$ for $24 \mathrm{~h}$ post-injection every 4 days except for PBS group. Tumor sizes and body weights were recorded every day. On the $14^{\text {th }}$ day after inoculation, all the tumor grafts were removed, weighed. a Schematic illustration of process of the chemo-radiation combined therapy; b SKOV-3 tumor growth curves of different groups after intravenously injection of the formulations; c The images of tumors isolated after treatment for 8 days; $\mathbf{d}$ Mean weights of the tumors isolated on day 14; e Body weight changes over the 8 days of the experiments

$\mathrm{Z}_{\mathrm{Her} 2}$ affibody was generated using a genetic engineering approach and successfully coupled to Pt@mPDA/ $/ \mathrm{MnO}_{2} /$ PDA NPs. Compared to the widely used intact antibody, this engineered affibody has the advantage of higher specific affinity, stronger tissue penetrability, higher synthetic yield at a lower price, and low immunogenicity $[48,50]$. Such affibodies can be employed to guide nanoagents for enhanced therapeutic efficacy. In addition, in 

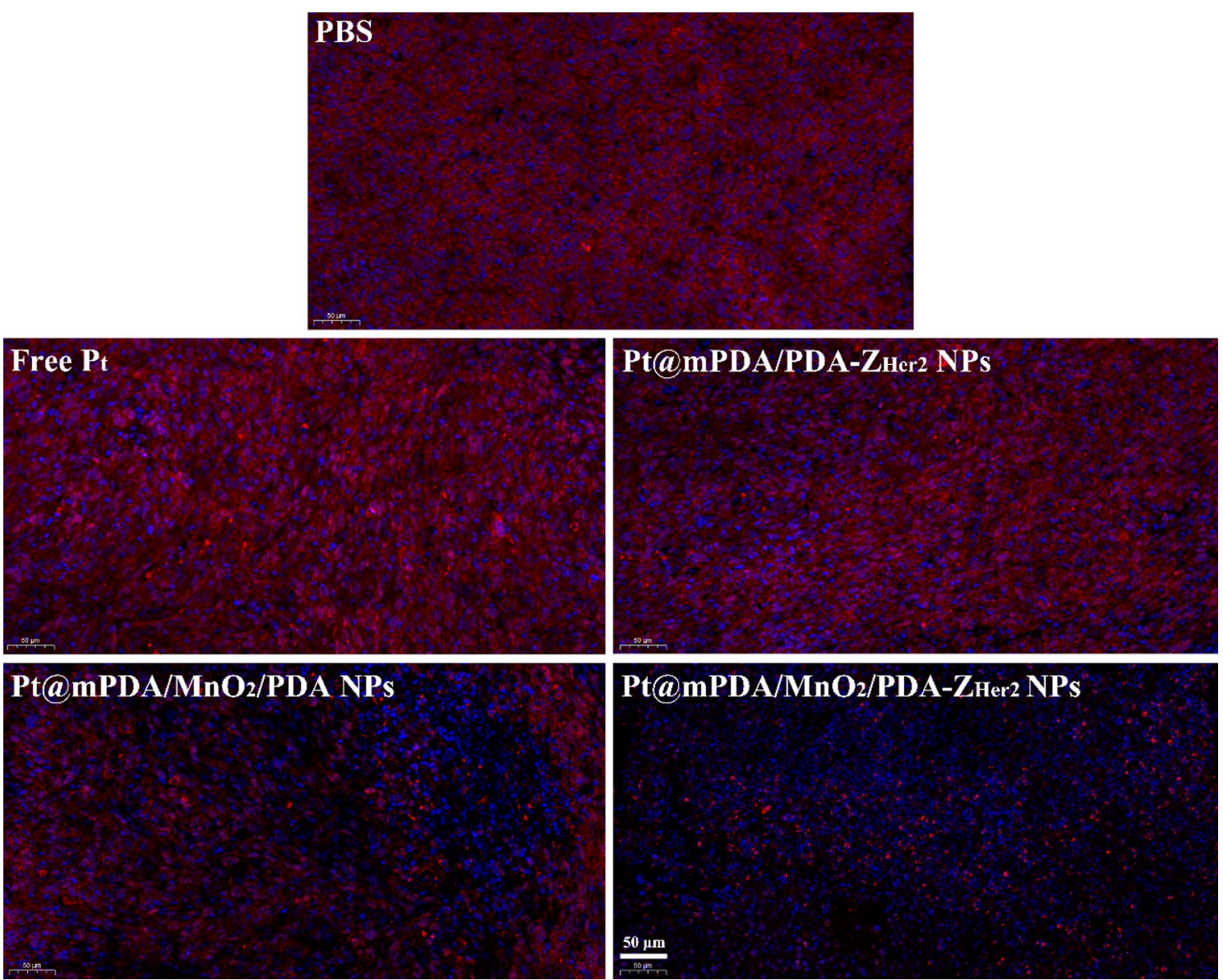

Fig. $9 \mathrm{Immunofluorescence} \mathrm{images} \mathrm{of} \mathrm{HIF-1a} \mathrm{(red)-stained} \mathrm{tumor} \mathrm{slices} \mathrm{excised} \mathrm{from} \mathrm{the} \mathrm{various} \mathrm{treatment} \mathrm{groups.} \mathrm{The} \mathrm{nuclei} \mathrm{of} \mathrm{cells} \mathrm{were}$ visualized using DAPI (blue)

marked contrast to monofunctional antibody-drug conjugates, the $\mathrm{Z}_{\mathrm{Her} 2}$ affibody with a nano-agent, which features specific targeting, RT sensitization, and diagnostic abilities, has been prepared and provide a new concept for clinical translation in tumor theranostics.

\section{Conclusion}

In the present study, Her2-targeted cisplatin-loaded mPDA $/ \mathrm{MnO}_{2} / \mathrm{PDA}$ NPs for MR imaging and enhanced chemo-radiotherapy of hypoxic tumors is reported. These NPs are biodegradable under a simulated tumor microenvironment, resulting in accelerated cisplatin release as well as $\mathrm{O}_{2}$ production by triggering decomposition of $\mathrm{H}_{2} \mathrm{O}_{2}$. Cell uptake experiments demonstrated that $\mathrm{Z}_{\mathrm{Her} 2}$ endowed the NPs with the ability to bind to Her2, achieving enhanced internalization of NPs into Her2-positive SKOV-3 cells. In vivo MRI studies revealed an obvious $T_{1}$ contrast enhancement at the tumor site of mice receiving the NPs. Immunofluorescence assays showed that the presence of $\mathrm{MnO}_{2}$ significantly reduced the expression of HIF- $1 \alpha$ and that the Cy5.5 fluorescently-labelled carrier has a high affinity for Her2. Chemotherapy results verified that Pt@mPDA $/ \mathrm{MnO}_{2} / \mathrm{PDA}-\mathrm{Z}_{\mathrm{Her} 2} \mathrm{NPs}$ have a strong targeted antitumor efficacy. Combined with X-ray irradiation, the Pt@mPDA $/ \mathrm{MnO}_{2} / \mathrm{PDA}-\mathrm{Z}_{\mathrm{Her} 2} \mathrm{NPs}$ can relieve tumor hypoxia and exhibit the superb inhibition of tumor growth. Hence, this multifunctional nanoplatform shows promising potential for clinical translation in tumor theranostics.

\section{Materials and methods}

Materials

Pluronic F127 (Mw: $12.6 \mathrm{kDa}$ ) was obtained from SigmaAldrich (USA). Dopamine hydrochloride (DA. $\mathrm{HCl}$ ), 1, 3, 5-trimethylbenzene (TMB), dimethyl sulfoxide (DMSO), cisplatin (Pt, 65\%), and cyanine-5.5 (Cy5.5) were purchased from Aladdin (Shanghai, China). Ammonium hydroxide (25.0-28.0\%), ethanol, potassium permanganate $\left(\mathrm{KMnO}_{4}\right)$, and hydrogen peroxide $\left(\mathrm{H}_{2} \mathrm{O}_{2}, 30 \% \mathrm{v} / \mathrm{v}\right)$ were procured from Sinopharm Chemical Reagent Co., 
Ltd (Shanghai, China). Isopropyl- $\beta$-d-thiogalactoside (IPTG), 2-mercaptoethanol (2-ME), 6-carboxyfluorescence (6-FAM), 3-(4,5-dimethylthiazol-2-yl)-2,5-diphenyltetrazoliumbromide (MTT), glutathione (GSH), 2,7-dichlorodi-hydrofluorescein diacetate (DCFH-DA), calcein-AM, and propidium iodide (PI) were sourced from Sigma-Aldrich (USA). High-glucose Dulbecco's modified Eagle's medium (DMEM), foetal bovine serum, penicillin and streptomycin, trypsin-ethylenediaminetetraacetic acid (trypsin-EDTA), and phosphate-buffered saline (PBS) were obtained from Gibco (Carlsbad, CA). Tris (hydroxymethyl) aminomethane buffer (Tris-buffer, $\mathrm{pH}$ 8.6) and McCoy's 5A medium supplemented with penicillin $(100 \mathrm{U} / \mathrm{mL})$ and streptomycin $(100 \mathrm{U} / \mathrm{mL})$ were acquired from Jiangsu KeyGEN BioTECH Co., Ltd (Nanjing, China). Human umbilical vein endothelial cells (HUVECs), breast cancer cell line MCF-7, and Her2positive human ovarian cancer cell line SKOV-3 were provided by the Type Culture Collection of the Chinese Academy of Sciences (Shanghai, China). Deionized (DI) water $(>18.2 \mathrm{M} \Omega \cdot \mathrm{cm})$ used for all experiments was purified using a Millipore system, and all chemicals were used without further purification.

\section{Preparation of Pt@mPDA/MnO $/ 2$ PDA NPs}

Mesoporous polydopamine nanoparticles (mPDA NPs) were synthesized according to a nano-emulsion assembly approach [51] with slight modifications. Pluronic F127 $(2.0 \mathrm{~g})$ and DA. $\mathrm{HCl}(1.0 \mathrm{~g})$ were dissolved in 50\% $\mathrm{v} / \mathrm{v}$ ethanol $(200 \mathrm{~mL})$ and stirred at $1000 \mathrm{rpm}$ for $3 \mathrm{~h}$. Then, TMB $(1 \mathrm{~mL})$ was added dropwise to the mixture and sonicated for $5 \mathrm{~min}$ to allow for generation of the nano-emulsion. After stirring for another $30 \mathrm{~min}$ at 500 rpm, $\mathrm{NH}_{4} \mathrm{OH}(10 \mathrm{~mL})$ was added to the resultant mixture while stirring under aerobic conditions to induce the selfpolymerization of dopamine. After another $3 \mathrm{~h}$ of continuous reaction and then centrifugation, the mPDA NPs were collected and washed thoroughly with absolute ethanol and then dispersed in PBS for further use. For drug loading, DMSO $(200 \mu \mathrm{L})$ containing cisplatin $(25 \mathrm{mg})$ was added to the mPDA NPs ( $50 \mathrm{mg}$ in $50 \mathrm{~mL}$ of PBS), followed by sonication for $30 \mathrm{~min}$, and stirring for $24 \mathrm{~h}$ in the dark. The cisplatin-loaded mPDA NPs (denoted Pt@mPDA NPs) were collected after centrifugation and washed with DI water.

The Pt@mPDA NPs were re-dispersed into DI water $(50 \mathrm{~mL}, \mathrm{pH} 7.4)$, and $\mathrm{KMnO}_{4}(50 \mathrm{mg})$ was added while stirring at $400 \mathrm{rpm}$ for $6 \mathrm{~h}$. After sonication for another $6 \mathrm{~h}$, the mixture was centrifuged and washed thoroughly with DI water, yielding Pt@mPDA/ $\mathrm{MnO}_{2}$ NPs. Finally, the Pt@mPDA $/ \mathrm{MnO}_{2} \mathrm{NPs}$ were re-dispersed in trisbuffer $(100 \mathrm{~mL}, \mathrm{pH}=8.6)$, and DA $(50 \mathrm{mg})$ was added.
The mixture was stirred (400 rpm) for $4 \mathrm{~h}$, and the NPs were washed with DI water. This yielded Pt@mPDA/ $\mathrm{MnO}_{2} / \mathrm{PDA}$ NPs, which were re-dispersed into DI water for further use.

\section{Preparation and characterization of the $Z_{\mathrm{Her} 2}$ affibody}

The $\mathrm{Z}_{\mathrm{Her} 2}$ affibody was expressed and purified according to our previous work [52], with some modifications. In detail, an artificial and optimized gene (5'-GCGGAG GCGAAGTACGCGAAAGAAATGCGTAACGCGTAT TGGGAGATCGCGCTGCTGCCGAACCTGACCAAC CAGCAAAAGCGTGCGTTCATTCGTAAACTGTAC GACGATCCGAGCCAGAGCAGCGAGCTGCTGAGC GAAGCG AAG AAA CTGAACGAC AGCCAA GCG CCGAAGTGC-3') encoding $Z_{\mathrm{Her} 2}$ affibody molecule with an added cysteine at the $\mathrm{C}$-terminus of protein was synthesized by GenScript (Nanjing, China) and cloned into pQE30 at the BamHI and SalI sites to construct the expression plasmid $\mathrm{pQE} 30-\mathrm{Z}_{\mathrm{Her} 2}$. The plasmid was transformed into $E$. coli M15 and induced overnight with $0.05 \mathrm{mM}$ IPTG at $28^{\circ} \mathrm{C}$. Subsequently, the cells were collected by centrifugation, resuspended in lysis buffer ( 50 $\mathrm{mM}$ phosphate, $\mathrm{pH} 8.0,300 \mathrm{mM} \mathrm{NaCl}$, and $20 \mathrm{mM}$ imidazole) and sonicated on ice for $30 \mathrm{~min}$ to lyse the cells. The recombinant protein in the supernatant was purified using Ni-NTA affinity chromatography according to the manufacturer's instructions (GenScript, Nanjing, China). The fractions collected during the $\mathrm{Z}_{\mathrm{Her} 2}$ preparation process were detected using sodium dodecyl sulphate polyacrylamide gel electrophoresis (SDS-PAGE) and analyzed using Image J software (Bethesda, MD, USA). The purified affibody was dialyzed against phosphatebuffered saline (PBS, $137 \mathrm{mM} \mathrm{NaCl}, 2.7 \mathrm{mM} \mathrm{KCl}, 4.3$ $\mathrm{mM} \mathrm{Na}_{2} \mathrm{HPO}_{4}$, and $1.4 \mathrm{mM} \mathrm{KH_{2 }} \mathrm{PO}_{4}, \mathrm{pH}$ 7.4) and then quantified using a Bradford Protein Assay Kit (Beyotime, Jiangsu, China).

The aggregation form of $\mathrm{Z}_{\mathrm{Her} 2}$ was detected using SDS-PAGE with or without 2-mercaptoethanol (2-ME) in the loading buffer. For the specific cell binding assay, $\mathrm{Z}_{\mathrm{Her} 2}$ was labelled with 6-FAM (Ruixi Biology, Xi'an, China) according to the manufacturer's protocol. In brief, 6-FAM $\left(10 \mu \mathrm{L} ; 10 \mathrm{mg} / \mathrm{mL}\right.$ in DMF) was added to $\mathrm{Z}_{\mathrm{Her} 2}$ solution $(5 \mathrm{~mL} ; 2 \mathrm{mg} / \mathrm{mL} ; \mathrm{pH} 8.3$ in PBS). The reaction was allowed to proceed for $1 \mathrm{~h}$ at $25^{\circ} \mathrm{C}$ in the dark before the mixture was dialyzed against $\mathrm{PBS}(\mathrm{pH} 7.4)$ at $4{ }^{\circ} \mathrm{C}$ for $48 \mathrm{~h}$ to remove unreacted 6-FAM. The conjugation of 6-FAM to the $Z_{\mathrm{Her} 2}$ affibody was verified by SDS-PAGE.

\section{Conjugation of $Z_{\text {Her2 }}$ affibody to NPs}

The Pt@mPDA/ $\mathrm{MnO}_{2} / \mathrm{PDA}-\mathrm{Z}_{\mathrm{Her} 2} \mathrm{NPs}$ were constructed by conjugating $\mathrm{Z}_{\mathrm{Her} 2}$ to Pt@mPDA $/ \mathrm{MnO}_{2} / \mathrm{PDA} \mathrm{NPs}$ via a Michael addition/Schiff base reaction between the amino group and the oxidized quinone form of catechol 
groups under weak alkaline $\mathrm{pH}$ conditions $[53,54]$. The $\mathrm{Pt} @ \mathrm{mPDA} / \mathrm{MnO}_{2} / \mathrm{PDA}$ NPs were dispersed in tris-buffer $(100 \mathrm{~mL}, 0.5 \mathrm{mg} / \mathrm{mL})$, and $\mathrm{Z}_{\mathrm{Her} 2}$ solution $(1 \mathrm{~mL} ; 1 \mathrm{mg} / \mathrm{mL}$ in PBS) was added, followed by sonication $(40 \mathrm{kHz}, 70$ $\mathrm{W})$ for $30 \mathrm{~min}$. The mixture was then stirred overnight at $25^{\circ} \mathrm{C}$. The unreacted $\mathrm{Z}_{\mathrm{Her} 2}$ was removed by centrifugation, and the NPs were thoroughly washed with DI water. This yielded Pt@mPDA $/ \mathrm{MnO}_{2} / \mathrm{PDA}-\mathrm{Z}_{\mathrm{Her}} \mathrm{NPs}$, which was re-dispersed in PBS for further use.

\section{Characterization of NPs}

The morphology of the NPs was observed by transmission electron microscopy (TEM, JEOL 2010F) at an accelerated voltage of $200 \mathrm{kV}$. The surface area and pore size of the mPDA NPs were measured using an automated surface area and porosity analyzer (Quantachrome, Autosorb-iQ). X-ray photoelectron spectroscopy (XPS) was performed using a Thermo Fisher ESCALAB 250Xi spectrometer to determine the chemical state of $\mathrm{MnO}_{2}$. Zeta potential and particle size distribution were measured using a Malvern Zetasizer (Nano-ZS, Malvern, UK). UV-Vis absorbance spectra were recorded on a UV-2100 spectrophotometer. The concentration of $\mathrm{MnO}_{2}$, cisplatin, and $\mathrm{Z}_{\mathrm{Her} 2}$ in the NPs were analyzed by measuring $\mathrm{Mn}, \mathrm{Pt}$, and $\mathrm{S}$ elements using inductively coupled plasma-atomic emission spectrometry (ICP-AES, Prodigy, LEEMAN).

\section{Biodegradation and in vitro drug release}

Pt@mPDA $/ \mathrm{MnO}_{2} / \mathrm{PDA}$ NPs were dispersed in PBS (50 $\mathrm{mL} ; \mathrm{pH}$ 7.4) and incubated with different concentration of either (1) $\mathrm{H}_{2} \mathrm{O}_{2}(1 \mathrm{mM})$; (2) $\mathrm{GSH}(2 \mathrm{mM})$; (3) $\mathrm{H}_{2} \mathrm{O}_{2}$ (1 $\mathrm{mM})$ and GSH (2 mM); (4) $\mathrm{H}_{2} \mathrm{O}_{2}(1 \mathrm{mM})$, GSH $(5 \mathrm{mM})$ at $37{ }^{\circ} \mathrm{C}$ with shaking at $120 \mathrm{rpm}$ for $14 \mathrm{~d}$. At each specified time point, a sample $(1 \mathrm{~mL})$ was removed for UV-Vis absorbance measurement. After 2 weeks, each sample was collected and the extent of degradation was determined using TEM.

The concentration of drug released from the NPs was measured according to the dialysis method described previously [14], with some modifications. In brief, Pt@ $\mathrm{mPDA} / \mathrm{MnO}_{2} / \mathrm{PDA}$ NPs $(3 \mathrm{mg})$ were dispersed in PBS (2 mL, pH 7.4) and then loaded into a dialysis bag $(\mathrm{MWCO}=7000 \mathrm{Da})$ and immersed in PBS $(18 \mathrm{~mL} ; \mathrm{pH}$ 7.4 and 5.5) containing different concentration of $\mathrm{H}_{2} \mathrm{O}_{2}$ $(0$ or $1 \mathrm{mM})$ and GSH $(0$ or $5 \mathrm{mM})$. All samples were incubated at $37{ }^{\circ} \mathrm{C}$ with shaking $(120 \mathrm{rpm})$ for 2 days. At predetermined time points, some external medium (1 $\mathrm{mL}$ ) was removed, and the samples were supplemented with an equal volume of fresh pre-heated medium. The free cisplatin release profile from dialysis bag was measured using the same method. The concentration of the released cisplatin was determined quantitatively by ICPAES. All experiments were performed in triplicate.

Measurement of dissolved $\mathrm{O}_{2}$ and detection of ROS in vitro The ability of $\mathrm{MnO}_{2}$-based NPs to catalyze the decomposition of $\mathrm{H}_{2} \mathrm{O}_{2}$ to $\mathrm{O}_{2}$ was measured using a dissolved oxygen meter (JPSJ-605, INESA).Pt@mPDA/ $\mathrm{MnO}_{2} /$ PDA NPs were dispersed in PBS (50 mL; pH 7.4 and 5.5; $\left.\left[\mathrm{MnO}_{2}\right]=2 \mu \mathrm{g} / \mathrm{mL}\right)$ and then transferred into a doubleneck flask. $\mathrm{H}_{2} \mathrm{O}_{2}(30 \% \mathrm{w} / \mathrm{v})$ was added at a final concentration of $1 \mathrm{mM}$. Blank PBS (pH 7.4) or PBS (pH 7.4) containing $\mathrm{H}_{2} \mathrm{O}_{2}$ was used as the control medium. The concentration of dissolved $\mathrm{O}_{2}$ was measured at predetermined time points.

The RT-sensitizing effect of $\mathrm{MnO}_{2}$-containing NPs caused by catalyzing the decomposition of $\mathrm{H}_{2} \mathrm{O}_{2}$ to $\mathrm{O}_{2}$ was measured using a methylene blue $(\mathrm{MB})$ degradation method. MB solution $(50 \mathrm{~mL} ; 10 \mu \mathrm{g} / \mathrm{mL})$ containing $\mathrm{H}_{2} \mathrm{O}_{2}(8 \mathrm{mM})$ was separately treated with (1) X-Ray (6 Gy), (2) Pt@mPDA/PDA-Z Her2 $_{\text {NPs }}$ (5 mg) +X-Ray (6 Gy), (3) Pt@mPDA $/ \mathrm{MnO}_{2} / \mathrm{PDA}-\mathrm{Z}_{\mathrm{Her} 2}$ (5 mg), (4) Pt@ $\mathrm{mPDA} / \mathrm{MnO}_{2} / \mathrm{PDA}-\mathrm{Z}_{\mathrm{Her} 2}(5 \mathrm{mg})+\mathrm{X}$-Ray (6 Gy). After incubation for $30 \mathrm{~min}$ at $37{ }^{\circ} \mathrm{C}$, the $\mathrm{MB}$ absorbance of each sample was measured.

\section{GSH-activated $\mathrm{T}_{1}$-weighted MRI}

Pt@mPDA $/ \mathrm{MnO}_{2} / \mathrm{PDA} \mathrm{NPs}$ at different concentrations of $\mathrm{Mn}([\mathrm{Mn}]=1 \mathrm{mM}, 2 \mathrm{mM}, 3 \mathrm{mM}, 4 \mathrm{mM}$, and $5 \mathrm{mM}$ in PBS) were each treated with or without $2 \mathrm{mM} \mathrm{GSH}$. After $20 \mathrm{~min}$, the $\mathrm{T}_{1}$-weighted relaxation times were measured using a $0.5 \mathrm{~T}$ NMI20 NMR Analyzing and Imaging system (Niumag, Shanghai, China) at $25^{\circ} \mathrm{C}$. The test parameters were set according to a previous publication [14]. $\mathrm{T}_{1}$ relaxivity $\left(\mathrm{r}_{1}\right)$ was acquired by fitting a linear function through $1 / T_{1}$ as a function of $M n$ concentration. In addition, $\mathrm{T}_{1}$ MRI was performed for samples at different concentrations using a clinical MR system (1.5 T, Siemens Magnetom Symphony).

\section{In vitro cellular uptake evaluation}

The expression of Her2 in the breast cancer cell line MCF-7 and the human ovarian cancer cell line SKOV-3 was evaluated. MCF-7 and SKOV-3 cells were incubated in DMEM or McCoy's 5A medium supplemented with $1 \% \mathrm{v} / \mathrm{v}$ penicillin, $1 \% \mathrm{v} / \mathrm{v}$ streptomycin, and $10 \% \mathrm{v} / \mathrm{v}$ foetal bovine serum. The cells were cultured at $37{ }^{\circ} \mathrm{C}$ in a $5 \% \mathrm{CO}_{2}$ humidified atmosphere. MCF-7 and SKOV-3 cells $\left(2 \times 10^{5}\right)$ were digested and resuspended in DMEM or McCoy's $5 \mathrm{~A}$ medium containing 2 or $4 \mu \mathrm{g} / \mathrm{mL}$ FITCanti-Her2 antibody (Sino Biological, Beijing, China) at 37 ${ }^{\circ} \mathrm{C}$ for $2 \mathrm{~h}$. After incubation, the cells were washed three times with PBS and resuspended in PBS $(0.5 \mathrm{~mL})$. The 
FITC fluorescence intensity was determined using a Becton-Dickinson FACScan analyzer (Frankin, CA, USA). Three independent experiments were conducted. Visualization of the distribution of FITC-anti-Her2 antibody in cells was further analyzed by confocal laser scanning microscopy (CLSM, Carl Zeiss LSM 700). Specifically, MCF-7 or SKOV-3 cells were seeded into 24-well plates and cultured at $37^{\circ} \mathrm{C}$. After $12 \mathrm{~h}$, the cells were incubated with 2 or $4 \mu \mathrm{g} / \mathrm{mL}$ FITC-anti-Her2 antibody for a further $2 \mathrm{~h}$. The cells were washed three times with PBS, fixed with $4 \%$ paraformaldehyde for $15 \mathrm{~min}$ at $4{ }^{\circ} \mathrm{C}$, and then washed again three times with PBS. Finally, the cells were immediately observed using CLSM.

The specific affinity between $Z_{\mathrm{Her} 2}$ and Her2-positive cancer cell lines was evaluated. Her2-negative MCF-7 cells or Her2-positive SKOV-3 cells were seeded in a confocal dish $\left(5 \times 10^{4}\right.$ cells per dish) and incubated for $12 \mathrm{~h}$. Thereafter, the medium was aspirated and replaced with fresh medium containing FAM-Z $\mathrm{Z}_{\mathrm{Her} 2}(2 \mathrm{~mL} ; 50 \mu \mathrm{g} / \mathrm{mL})$. After another $2 \mathrm{~h}$ of incubation, the cells were washed three times with PBS and then fixed with $4 \%$ paraformaldehyde for $15 \mathrm{~min}$ at $4{ }^{\circ} \mathrm{C}$. The cell nuclei were stained with DAPI $(1 \mathrm{~mL}, 10 \mu \mathrm{g} / \mathrm{mL})$ for $5 \mathrm{~min}$ and then washed three times with PBS. Finally, the cells were immediately observed using CLSM. The affinity between FAM-Z $\mathrm{Z}_{\text {Her2 }}$ and SKOV-3 cells was also evaluated by flow cytometry (FCM). Approximately $2 \times 10^{5}$ digested cells were incubated with FAM-Z $\mathrm{Her}(50 \mu \mathrm{g} / \mathrm{mL})$ at $37^{\circ} \mathrm{C}$ for $2 \mathrm{~h}$. For Her2 receptor blocking experiments, SKOV-3 cells were pre-incubated with $Z_{\mathrm{Her} 2}(20 \mu \mathrm{g} / \mathrm{mL})$ for $1 \mathrm{~h}$ and then incubated with FAM-Z $Z_{\text {Her2 }}(50 \mu \mathrm{g} / \mathrm{mL})$ for another $2 \mathrm{~h}$. After that, the cells were washed three times with PBS and re-dispersed in PBS $(0.5 \mathrm{~mL})$ for FCM assay.

FCM was used to evaluate the affinity of monomeric and dimeric affibodies to Her2 receptors. Briefly, SKOV-3 cells $\left(2 \times 10^{5}\right)$ were digested and incubated with the same molar concentration $(100 \mathrm{nM})$ of monomeric (in the presence of 2-ME) or dimeric (in the absence of 2-ME) FAM-Her 2 affibody at $37^{\circ} \mathrm{C}$ for $2 \mathrm{~h}$. After incubation, the cells were washed three times with PBS and redispersed in PBS $(0.5 \mathrm{~mL})$. The FAM fluorescence intensity was determined by FCM.

To visually track the distribution of the NPs in cells, Cy5.5-loaded NPs (Cy5.5@mPDA/ $/ \mathrm{MnO}_{2} / \mathrm{PDA}$ or Cy5.5@mPDA $/ \mathrm{MnO}_{2} / \mathrm{PDA}-\mathrm{Z}_{\mathrm{Her} 2} \mathrm{NPs}$ ) were prepared following the same method as described above. The SKOV-3 cellular uptake of these NPs was evaluated following a protocol similar to that described above, except that an FBS-free medium containing Cy5.5@mPDA/ $\mathrm{MnO}_{2} / \mathrm{PDA}$ or $\mathrm{Cy} 5.5 @ \mathrm{mPDA} / \mathrm{MnO}_{2} / \mathrm{PDA}-\mathrm{Z}_{\mathrm{Her} 2} \mathrm{NPs}$ $(50 \mu \mathrm{g} / \mathrm{mL}$; in PBS) was added after the initial culture. To investigate Her2-dependent binding, SKOV-3 cells were pre-incubated with free $Z_{\mathrm{Her} 2}(20 \mu \mathrm{g} / \mathrm{mL})$ for $1 \mathrm{~h}$ prior to incubation with Cy5.5@mPDA $/ \mathrm{MnO}_{2} / \mathrm{PDA}-\mathrm{Z}_{\mathrm{Her} 2} \mathrm{NPs}$ $(50 \mu \mathrm{g} / \mathrm{mL})$. Finally, the cells were treated and probed by CLSM as described above.

FCM was performed to semi-quantify the uptake of these two NPs by SKOV-3 cells. Approximately $2 \times 10^{5}$ cells were incubated with Cy5.5@mPDA/ $\mathrm{MnO}_{2} / \mathrm{PDA}$ or Cy5.5@mPDA/ $\mathrm{MnO}_{2} / \mathrm{PDA}-\mathrm{Z}_{\mathrm{Her} 2} \mathrm{NPs}(50 \mu \mathrm{g} / \mathrm{mL}$; in PBS) after a $1 \mathrm{~h}$ pre-treatment with or without free $Z_{\mathrm{Her} 2}$ $(20 \mu \mathrm{g} / \mathrm{mL})$. After $4 \mathrm{~h}$ incubation at $37^{\circ} \mathrm{C}$, the cells were washed three times with PBS and re-dispersed in $0.5 \mathrm{~mL}$ PBS for FCM analysis.

\section{Cytotoxicity assays}

The cytocompatibility of drug-free $\mathrm{mPDA} / \mathrm{MnO}_{2} / \mathrm{PDA}$ $\mathrm{Z}_{\mathrm{Her} 2}$ NPs to HUVECs was first determined by performing the MTT assay. HUVECs $\left(\sim 1 \times 10^{4}\right)$ were seeded into 96-well plates and cultured overnight at $37{ }^{\circ} \mathrm{C}$ in a $5 \%$ $\mathrm{CO}_{2}$ humidified environment. The medium was replaced with fresh DMEM $(200 \mu \mathrm{L})$ containing different concentrations of mPDA $/ \mathrm{MnO}_{2} / \mathrm{PDA}-\mathrm{Z}_{\mathrm{Her} 2} \mathrm{NPs}(1,5,10,20$, 50,100 , and $250 \mu \mathrm{g} / \mathrm{mL}$ ), and the cells were incubated for another $24 \mathrm{~h}$. Subsequently, the medium of each well was carefully discarded followed by the addition of MTT solution $(20 \mu \mathrm{L}, 10 \mu \mathrm{g} / \mathrm{mL})$, and the cells were incubated for an additional $4 \mathrm{~h}$. Finally, DMSO $(200 \mu \mathrm{L})$ was added after removing the medium, and the absorbance of the wells at $570 \mathrm{~nm}$ was measured with a microplate reader (Multiskan FC, Thermo Scientific).

The in vitro anticancer efficacy of different cisplatin formulations was investigated using a method similar to that described above, except that medium $(200 \mu \mathrm{L})$ containing free cisplatin, Pt@mPDA/ $\mathrm{MnO}_{2} / \mathrm{PDA} \mathrm{NPs}$, or $\mathrm{Pt} @ \mathrm{mPDA} / \mathrm{MnO}_{2} / \mathrm{PDA}-\mathrm{Z}_{\mathrm{Her} 2} \mathrm{NPs}$ ([cisplatin] =0.6, 3, $6,12,24$, or $48 \mu \mathrm{g} / \mathrm{mL}$ ) was added after the initial incubation. Data are reported as mean \pm S.D., with three independently performed experiments each containing three replicates. The cells treated with free cisplatin, Pt@ $\mathrm{mPDA} / \mathrm{MnO}_{2} / \mathrm{PDA} \mathrm{NPs}$, or Pt@mPDA $/ \mathrm{MnO}_{2} / \mathrm{PDA}$ $\mathrm{Z}_{\mathrm{Her} 2}$ NPs ([cisplatin] $=48 \mu \mathrm{g} / \mathrm{mL}$ ) for $24 \mathrm{~h}$ were further stained with PI (staining dead cells red) and calcein-AM (staining live cells green) in PBS solution for $30 \mathrm{~min}$ at 37 ${ }^{\circ} \mathrm{C}$ in the dark and then imaged by inverted fluorescence microscopy (Carl Zeiss). For all experiments, PBS-treated cells were used as the control.

\section{Measurement of intracellular ROS levels}

The levels of intracellular ROS were measured using DCFH-DA to evaluate the RT-sensitizing effect of $\mathrm{MnO}_{2}$. SKOV-3 cells were seeded onto 24-well plates at 50,000 cells/well and maintained in McCoy's 5A medium. After $12 \mathrm{~h}$ incubation at $37{ }^{\circ} \mathrm{C}$, cells were treated with either (1) PBS, (2) $\mathrm{PBS}+\mathrm{X}$-ray, (3) $\mathrm{MnO}_{2}$-free mPDA/PDA$\mathrm{Z}_{\mathrm{Her} 2} \mathrm{NPs}\left(50 \mu \mathrm{g} / \mathrm{mL}\right.$; in PBS) + X-ray, (4) $\mathrm{mPDA} / \mathrm{MnO}_{2} /$ 
PDA-Z $\mathrm{Her}_{2}$ NPs $(50 \mu \mathrm{g} / \mathrm{mL}$; in PBS), and (5) mPDA/ $\mathrm{MnO}_{2} / \mathrm{PDA}-\mathrm{Z}_{\mathrm{Her} 2} \mathrm{NPs}(50 \mu \mathrm{g} / \mathrm{mL}$; in $\mathrm{PBS})+\mathrm{X}$-ray. In samples receiving $\mathrm{X}$-ray treatment, the cells were irradiated with X-rays (6 Gy) after $4 \mathrm{~h}$ of incubation. After an additional $1 \mathrm{~h}$ of incubation, DCFH-DA solution $(1 \mathrm{~mL}$; $10 \mu \mathrm{M})$ was added to the cells for another $30 \mathrm{~min}$. Subsequently, the fluorescence images were acquired with inverted fluorescence microscopy (Carl Zeiss).

\section{Hemocompatibility assay}

Fresh blood was obtained from female Sprague-Dawley (SD) rats and centrifuged at $1500 \mathrm{rpm}$ for $15 \mathrm{~min}$ to separate red blood cells (RBCs). RBCs were then treated with a suspension of Pt@mPDA/MnO $/$ PDA NPs or Pt@ $\mathrm{mPDA} / \mathrm{MnO}_{2} / \mathrm{PDA}-\mathrm{Z}_{\mathrm{Her} 2} \mathrm{NPs}$ in PBS $(5 \mathrm{~mL}, 250 \mu \mathrm{g} /$ $\mathrm{mL})$. PBS (5 mL; pH 7.4) and Triton X-100 (5 mL; $1 \%$ $\mathrm{w} / \mathrm{v}$ ) were used as negative controls and positive controls, respectively. Each sample was incubated at $37{ }^{\circ} \mathrm{C}$ for $1 \mathrm{~h}$, and the intact RBCs were separated by centrifugation (1500 rpm; $15 \mathrm{~min})$. The supernatant from each tube was collected and the amount of hemoglobin release was determined by reading the absorbance at $540 \mathrm{~nm}$ in a microplate reader (Multiskan FC, Thermo Scientific). The formula below was used to calculate the percentage of RBC hemolysis and each experiment was conducted in triplicate.

$$
\begin{aligned}
\text { Hemolysis } \%= & (\mathrm{OD}[\text { test }]-\mathrm{OD}[\text { negative control }]) \\
& \times 100 / \mathrm{OD}[\text { positive control] }
\end{aligned}
$$

\section{Animals and tumor model}

All animal experiments were carried out with full authorization by the ethics committee for animal care of Shandong Cancer Hospital and Institute Shandong, First Medical University and Shandong Academy of Medical Sciences (Approval No. SDTHEC2020004083). Female BALB/C nude mice (SPF grade, 4-6 weeks old) were acquired from Beijing Huafukang Bioscience Co. Inc. (Beijing, China). Tumors were established by subcutaneous injection of SKOV-3 cells $\left(1 \times 10^{6}\right)$ dispersed in PBS $(100 \mu \mathrm{L})$ into the right flank of each mouse. The tumor volume was monitored in real-time and calculated as length $\times$ width $^{2} / 2$.

\section{In vivo MRI and biodistribution}

In order to demonstrate the TME-triggered MRI ability of the $\mathrm{MnO}_{2}$ layer, PBS $(50 \mu \mathrm{L})$ containing Pt@mPDA/ $\mathrm{MnO}_{2} / \mathrm{PDA} \mathrm{NPs}([\mathrm{Mn}]=50 \mathrm{mM})$ was indirectly injected into the tumor sites or the muscle on the opposite side to the tumors. At pre-determined time points $(0 \mathrm{~min}, 5 \mathrm{~min}$, and $120 \mathrm{~min}$ ), the SKOV-3 tumor-bearing mice were scanned using an MR analysis and imaging system (1.5 T, Siemens Magnetom Symphony).

When the tumor volume reached approximately 200 $\mathrm{mm}^{3}$, Pt@mPDA $/ \mathrm{MnO}_{2} / \mathrm{PDA} \mathrm{NPs}$ or Pt@mPDA $/ \mathrm{MnO}_{2} /$ PDA- $\mathrm{Z}_{\mathrm{Her} 2} \mathrm{NPs}([\mathrm{Mn}]=3 \mathrm{mM}, 100 \mu \mathrm{L}$ in PBS per mouse) were intravenously injected into the tumor-bearing mice, and $\mathrm{T}_{1}$-weighted $\mathrm{MR}$ images were obtained at different time points after injection. The following MR scanning parameters were used: $\mathrm{TE}=16.9 \mathrm{~ms}, \mathrm{TR}=760 \mathrm{~ms}$, FOV $=10 \mathrm{~cm} \times 10 \mathrm{~cm}$, slice thickness $=3 \mathrm{~mm}$, and point resolution $=512 \mathrm{~mm} \times 512 \mathrm{~mm}$.

The mice were sacrificed at $12 \mathrm{~h}$ after receiving NPs, and the heart, liver, spleen, lung, kidney, brain, muscle, and tumors were extracted and weighed and then dissolved in aqua regia solution $\left(2 \mathrm{~mL}, 65^{\circ} \mathrm{C}\right)$ for $24 \mathrm{~h}$. The mice intravenously injected with free cisplatin $(200 \mu \mathrm{L}$; $200 \mu \mathrm{g} / \mathrm{mL}$ in PBS) were used as control group. Finally, the Pt content in each tissue and tumor was quantified by ICP-AES.

\section{Immunofluorescence and bio-TEM assays}

The SKOV-3 tumor-bearing mice were intravenously injected with PBS containing Cy5.5@mPDA/ $\mathrm{MnO}_{2} / \mathrm{PDA}$ NPs or Cy5.5@mPDA $/ \mathrm{MnO}_{2} / \mathrm{PDA}-\mathrm{Z}_{\mathrm{Her} 2} \mathrm{NPs}(100 \mu \mathrm{L}$; $1 \mathrm{mg} / \mathrm{mL}$ ). For the immunofluorescence assay, tumors were collected at $12 \mathrm{~h}$ post-injection and fixed with OCT (Sakura) for cryo-sectioning. The tumor sections were incubated overnight with a rabbit anti-mouse Her2 primary antibody (dilution 1:200, Abcam) at $4{ }^{\circ} \mathrm{C}$ and then for $60 \mathrm{~min}$ with a goat anti-rabbit secondary antibody (dilution 1:200, Abcam) at $37{ }^{\circ} \mathrm{C}$. The cell nuclei were stained with DAPI. Finally, the obtained slices were scanned using an imaging system (Nikon DS-U3).

For bio-TEM, tumors were treated with $1 \% \mathrm{OsO}_{4}$ for 2 $\mathrm{h}$ at $25{ }^{\circ} \mathrm{C}$, then embedded in resin after the cells were dehydrated. Ultrathin sections $(70-90 \mathrm{~nm})$ of tumor tissue were cut and analyzed by bio-TEM (Hitachi HT7700, Tokyo, Japan).

\section{In vivo antitumor efficacy and safety evaluation}

When the volume of tumors reached $50 \mathrm{~mm}^{3}$, the tumor-bearing mice were randomly divided into four groups $(\mathrm{n}=5)$ and intravenously injected with either (1) PBS, (2) free cisplatin in PBS, (3) Pt@mPDA/ $\mathrm{MnO}_{2} / \mathrm{PDA}$ NPs in PBS, or (4) Pt@mPDA/ $\mathrm{MnO}_{2} / \mathrm{PDA}-\mathrm{Z}_{\mathrm{Her} 2} \mathrm{NPs}$ in PBS $(200 \mu \mathrm{L}$; dose of cisplatin $=2 \mathrm{mg} / \mathrm{kg})$ every 2 days. Tumor volume and body weights were monitored and recorded every day after the first injection. On the $14^{\text {th }}$ day, $0.5 \mathrm{~mL}$ of blood from each group of mice $(\mathrm{n}=3)$ was withdrawn, after which the experiment was halted. The tumors were collected and stained with terminal deoxynucleotidyl transferase UTP nick end labelling (TUNEL) for the apoptosis assay, while the major organs 
(heart, liver, spleen, lung, and kidney) were extracted and stained with haematoxylin and eosin (H\&E) for histological analysis.

For chemo-radiation combined therapy, when the volume of tumors reached $\sim 50 \mathrm{~mm}^{3}$, four groups of tumorbearing mice $(\mathrm{n}=5)$ were treated with either (5) PBS (200 $\mu \mathrm{L}),(6) \mathrm{PBS}(200 \mu \mathrm{L})+\mathrm{X}$-ray, (7) $\mathrm{MnO}_{2}$-free Pt@mPDA/ PDA-Z $\mathrm{H}_{\mathrm{Her} 2}$ NPs in PBS $(200 \mu \mathrm{L})+\mathrm{X}$-ray, or (8) Pt@ $\mathrm{mPDA} / \mathrm{MnO}_{2} / \mathrm{PDA}-\mathrm{Z}_{\mathrm{Her} 2} \mathrm{NPs}$ in PBS $(200 \mu \mathrm{L})+\mathrm{X}$-ray. All groups of mice except for group (5) received cisplatin and $\mathrm{MnO}_{2}$ doses of $2 \mathrm{mg} / \mathrm{kg}$ and $3.4 \mathrm{mg} / \mathrm{kg}$, respectively, every 2 days. For radiotherapy, mice received X-ray radiation at a dose of $6 \mathrm{~Gy}$ for $24 \mathrm{~h}$ post-injection every 4 days. Tumor sizes and body weights were recorded every day. After 14 days the mice were sacrificed, and tumors were collected for volume measurement and weighing. Finally, to evaluate tumor hypoxia levels, the tumor tissues from groups (1)-(4) and group (7) were HIF-1 $\alpha$ stained according to the manufacturer's instructions.

\section{Statistical analysis}

All results are presented as mean \pm standard deviation (S.D.), and between-group comparisons were evaluated using one-way ANOVA. A p value $<0.05$ indicates statistical significance, and data are represented as (*) for $\mathrm{p}<0.05$, ${ }^{(* *)}$ ) for $\mathrm{p}<0.01$, and $\left({ }^{* * * *}\right)$ for $\mathrm{p}<0.001$. NS stands for not statistically significant.

\author{
Abbreviations \\ RT: Radiotherapy; ROS: Reactive oxygen species; TME: Tumor microenviron- \\ ment; HIF-1a: Hypoxia-inducible factor 1a; MRI: Magnetic resonance imaging; \\ Her2: Human epidermal growth factor receptor 2; Pt: Cisplatin; mPDA: \\ Mesoporous polydopamine.
}

\section{Supplementary Information}

The online version contains supplementary material available at https://doi. org/10.1186/s12951-021-00885-6.

Additional file 1: Fig. S1. (a) $N_{2}$ adsorption/desorption isotherms of mPDA NPs and (b) the corresponding pore-size distribution curves. (c) Zeta potential values of cisplatin, mPDA, Pt@mPDA, Pt@mPDA/MnO 2 and Pt@mPDA $/ \mathrm{MnO}_{2} / \mathrm{PDA}$ NPs dispersed in water ( $\mathrm{pH}$ 7.4). Fig. S2. (a) XPS full survey spectra and (b) Mn $2 p$ XPS spectra of $\mathrm{mPDA} / \mathrm{MnO}_{2} / \mathrm{PDA}$ NPs. Fig. S3. UV-Vis absorption spectra of Pt@mPDA/MnO $/$ PDA NPs in (a) blank PBS (pH 7.4) and PBS (pH 7.4) containing (b) $1 \mathrm{mM} \mathrm{H}_{2} \mathrm{O}_{2}$, (c) $2 \mathrm{mM} \mathrm{GSH}$, (d) $1 \mathrm{mM} \mathrm{H}_{2} \mathrm{O}_{2}+2 \mathrm{mM} \mathrm{GSH}$, and (e) $1 \mathrm{mM} \mathrm{H}_{2} \mathrm{O}_{2}+5 \mathrm{mM} \mathrm{GSH}$ at different time points; ( $\mathrm{f}$ ) the absorption spectra comparison of aqueous dispersions of NPs after $14 \mathrm{~d}$ under different conditions. Fig. S4. UV-Vis absorption spectra of MB solution after treating with X-ray (6 Gy), Pt@mPDA/PDA $\mathrm{NPs}+\mathrm{X}$-ray (6 Gy), Pt@mPDA/MnO $2 / \mathrm{PDA}$ NPs, and Pt@mPDA/MnO $2 / \mathrm{PDA}$ $\mathrm{NPs}+\mathrm{X}$-ray (6 Gy) for $30 \mathrm{~min}$. Blank MB solution was used as control. Fig. S5. (a) DLS sizes of Pt@mPDA/MnO $/ 2$ PDA and Pt@mPDA/MnO $/$ PDA$Z_{\text {Her } 2}$ NPs in water. (b) DLS sizes of Pt@mPDA/MnO $/$ PDA and Pt@mPDA/ $\mathrm{MnO}_{2} / \mathrm{PDA}-\mathrm{Z}_{\text {Her2 } 2} \mathrm{NPs}$ in PBS over 24 h; Fig. S6. FCM data for (a) MCF-7 or (b) SKOV-3 cells after treatment with PBS, 2 or $4 \mu \mathrm{g} / \mathrm{mL}$ of FITC-labelled anti-Her 2 antibody for $2 \mathrm{~h}$ and showing the corresponding quantified fluorescence intensity. (c) Fluorescence images for MCF-7 or SKOV-3 cells after treatment with PBS and 2 or $4 \mathrm{\mu g} / \mathrm{mL}$ of FITC-labelled anti-Her2 antibody for 2 h. Fig. S7. (a) CLSM images of MCF-7 and SKOV-3 cells after $2 \mathrm{~h}$ incubation with FAM- $\mathrm{Z}_{\text {Her2. }}$. (b) Flow cytometry data for: untreated SKOV-3 cells; SKOV-3 cells incubated for $2 \mathrm{~h}$ with FAM-Z $Z_{\text {Her } 2}$ and cells pre-incubated with $Z_{\text {Her2 } 2}$ for $1 \mathrm{~h}$ before being exposed to FAM- $Z_{\text {Her } 2}$ for 2 $\mathrm{h}$, and corresponding quantified fluorescence intensity. Fig. S8. (a) Flow cytometry data for: untreated SKOV-3 cells; SKOV-3 cells incubated for monomeric (in the presence of 2-ME) or dimeric (in the absence of 2-ME) FAM-Her2 affibody at $37^{\circ} \mathrm{C}$ for $2 \mathrm{~h}$. (b) MTT viability results for HUVECs treated with different concentration of $\mathrm{mPDA} / \mathrm{MnO}_{2} / \mathrm{PDA}-\mathrm{Z}_{\mathrm{Her} 2} \mathrm{NPs}$. Fig. 59. (a) Microscope images of RBCs incubated with (II) PBS, (II) Triton-100, (III) Pt@mPDA/MnO $2 / P D A N P s$, (IV) Pt@mPDA/MnO $2 / P D A-Z_{\text {Her2 }}$ NPs and (b) corresponding pictures after centrifugation (5000 rpm, $10 \mathrm{~min}$ ). (c) Hemocompatibility data. Fig. S10. Biodistribution of free cisplatin (Pt), Pt@ $\mathrm{mPDA} / \mathrm{MnO}_{2} / \mathrm{PDA}$ and Pt@mPDA/MnO $2 / \mathrm{PDA}-\mathrm{Z}_{\mathrm{Her} 2} \mathrm{NPs}$ in mice bearing SKOV-3 tumor grafts. Fig. S11. Representative H\&E-stained images of the major organs collected after in vivo chemotherapy experiment. Fig. S12. Blood biochemical analyses of the mice from chemotherapy experiment.

\section{Acknowledgements}

The authors would like to thank the Professor David Bremner for his assistance in revision of the manuscript and Instrumental Analysis Centre of Donghua University for materials testing.

\section{Authors' contributions}

HW, QF and LZ designed the experiment, analyzed the data and drafted the manuscript. HW prepared and characterized the Pt@mPDA/MnO $/ 2 / P D A-Z_{\text {Her2 }}$ $N P S, F W$ and DJ prepared $Z_{\text {Her2 }}$. HW and QF performed the animal experiments. $D Y, X Y, F Y, W N$ and NL assisted with the in vitro and in vivo experiments. All authors read and approved the final manuscript.

\section{Funding}

This investigation was supported by the Youth Outstanding Reserve Talents Program of Shandong First Medical University and Shandong Academy of Medical Sciences, the grant 16410723700 from the Science and Technology Commission of Shanghai Municipality, Natural Science Foundation of Shandong Province (ZR2019PH006, ZR2020QH347), Youth Innovative Science and Technology Program of Shandong Colleges and University (2019KJM012), the Shandong Provincial Key Research Development Program (2018GSF1 18175).

\section{Availability of data and materials}

All data generated or analyzed during this study are included in this published article.

\section{Declarations}

Ethics approval and consent to participate

All animal experiments were carried out with full authorization approved by the ethical committee for animal care of Shandong Cancer Hospital and Institute Shandong, First Medical University and Shandong Academy of Medical Sciences (Approval No. SDTHEC2020004083).

\section{Consent for publication}

All authors agree to be published.

\section{Competing interests}

The authors declare that they have no competing interests.

\section{Author details}

'Department of Pharmacy, Shandong Cancer Hospital and Institute, Shandong First Medical University and Shandong Academy of Medical Sciences, Jinan 250117, China. ${ }^{2}$ College of Chemistry, Chemical Engineering and Biotechnology, Donghua University, Shanghai 201620, China. ${ }^{3}$ Laboratory of Drug Discovery and Design, School of Pharmacy, Liaocheng University, Liaocheng 252000, China. ${ }^{4}$ School of Life Sciences, Shandong First Medical University and Shandong Academy of Medical Sciences, Taian 271016, China. ${ }^{5}$ Department of Digestive Oncology, Shandong Cancer Hospital and Institute, Shandong First Medical University and Shandong Academy of Medical 
Sciences, Jinan 250117, China. ${ }^{6}$ Joint Laboratory for Translational Medicine Research, Liaocheng People's Hospital, Liaocheng 252000, China.

Received: 8 February 2021 Accepted: 6 May 2021 Published online: 13 May 2021

\section{References}

1. Ross G. Induction of cell death by radiotherapy. Endocr Relat Cancer. 1999:6:41-4.

2. LiY, Yun K-H, Lee H, Goh S-H, Suh Y-G, Choi Y. Porous platinum nanoparticles as a high-Z and oxygen generating nanozyme for enhanced radiotherapy in vivo. Biomaterials. 2019;197:12-9.

3. Herrera FG, Bourhis J, Coukos G. Radiotherapy combination opportunities leveraging immunity for the next oncology practice. CA Cancer J Clin. 2017;67:65-85.

4. Harrington KJ, Billingham $L$, Brunner TB, Burnet NG, Chan $\mathrm{CS}$, Hoskin P, Mackay RI, Maughan TS, Macdougall J, Mckenna WG. Guidelines for preclinical and early phase clinical assessment of novel radiosensitisers. Brit J Cancer. 2011;105:628-39.

5. Barker HE, Paget JT, Khan AA, Harrington KJ. The tumour microenvironment after radiotherapy: mechanisms of resistance and recurrence. Nat Rev Cancer. 2015;15:409-25.

6. Semenza GL. Intratumoral hypoxia, radiation resistance, and HIF-1. Cancer Cell. 2004;5:405-6.

7. Maier A, Anegg U, Fell B, Rehak P, Ratzenhofer B, Tomaselli F, Sankin O, Pinter H, Smolle-Jüttner FM, Friehs GB. Hyperbaric oxygen and photodynamic therapy in the treatment of advanced carcinoma of the cardia and the esophagus. Laser Surg Med. 2015;26:308-15.

8. Alwaili NS, Butler GJ, Beale J, Hamilton RW, Lee BY, Lucas P. Hyperbaric oxygen and malignancies: a potential role in radiotherapy, chemotherapy, tumor surgery and phototherapy. Med Sci Monit. 2005;11:RA279-289.

9. Fingar VH, Mang TS, Henderson BW. Modification of photodynamic therapy-induced hypoxia by Fluosol-DA (20\%) and carbogen breathing in mice. Cancer Res. 1988;48:3350-4.

10. Goswami N, Luo Z, Yuan X, Leong DT, Xie J. Engineering gold-based radiosensitizers for cancer radiotherapy. Mater Horiz. 2017;4:817-31.

11. Yang B, Chen Y, Shi J. Nanocatalytic medicine. Adv Mater. 2019;31:e1901778.

12. Gao M, Liang C, Song X, Chen Q, Jin Q, Wang C, Liu Z. Erythrocyte-membrane-enveloped perfluorocarbon as nanoscale artificial red blood cells to relieve tumor hypoxia and enhance cancer radiotherapy. Adv Mater. 2017;29:1701429.

13. Chen Q, Chen J, Yang Z, Xu J, Xu L, Liang C, Han X, Liu Z. Nanoparticleenhanced radiotherapy to trigger robust cancer immunotherapy. Adv Mater. 2019;31:e1802228.

14. Wang H, Bremner DH, Wu K, Gong X, Fan Q, Xie X, Zhang H, Wu J, Zhu L-M. Platelet membrane biomimetic bufalin-loaded hollow $\mathrm{MnO}_{2}$ nanoparticles for MRI-guided chemo-chemodynamic combined therapy of cancer. Chem Eng J. 2020;382:122848.

15. Lin LS, Song J, Song L, Ke K, Liu Y, Zhou Z, Shen Z, Li J, Yang Z, Tang W, et al. simultaneous fenton-like ion delivery and glutathione depletion by $\mathrm{MnO}_{2}$-based nanoagent enhances chemodynamic therapy. Angew Chem Int Ed Engl. 2018;57:4902-6.

16. Alizadeh N, Salimi A. Multienzymes activity of metals and metal oxide nanomaterials: applications from biotechnology to medicine and environmental engineering. J Nanobiotechnol. 2021;19:26.

17. Yang X, Yang Y, Gao F, Wei JJ, Qian CG, Sun MJ. Biomimetic hybrid nanozymes with self-supplied $\mathrm{H}(+)$ and accelerated $\mathrm{O}_{2}$ generation for enhanced starvation and photodynamic therapy against hypoxic tumors. Nano Lett. 2019;19:4334-42.

18. Wang D, Wu H, Lim WQ, Phua SZF, Xu P, Chen Q, Guo Z, Zhao Y. A mesoporous nanoenzyme derived from metal-organic frameworks with endogenous oxygen generation to alleviate tumor hypoxia for significantly enhanced photodynamic therapy. Adv Mater. 2019;31:e1901893.

19. Chen Q, Feng L, Liu J, Zhu W, Dong Z, Wu Y, Liu Z. Intelligent albumin$\mathrm{MnO}_{2}$ nanoparticles as $\mathrm{pH}-/ \mathrm{H}_{2} \mathrm{O}_{2}$-responsive dissociable nanocarriers to modulate tumor hypoxia for effective combination therapy. Adv Mater. 2016;28:7129-36.
20. Sun $Q$, Wang Z, Liu B, Jia T, Yang P. Self-generation of oxygen and simultaneously enhancing photodynamic therapy and MRI effect: an intelligent nanoplatform to conquer tumor hypoxia for enhanced phototherapy. Chem Eng J. 2020;390:124624.

21. Yang $G, X u L$, Chao Y, Xu J, Sun X, Wu Y, Peng R, Liu Z. Hollow $\mathrm{MnO}_{2}$ as a tumor-microenvironment-responsive biodegradable nano-platform for combination therapy favoring antitumor immune responses. Nat Commun. 2017;8:902.

22. Falk S. Principles of cancer treatment by radiotherapy. Surg Infect (Larchmt). 2003;21:269-72.

23. Vlahov IR, Leamon CP. Engineering folate-drug conjugates to target cancer: from chemistry to clinic. Bioconjug Chem. 2012;23:1357-69.

24. Fang $Y$, Jiang $Y$, Zou Y, Meng F, Zhang J, Deng C, Sun H, Zhong Z. Targeted glioma chemotherapy by cyclic RGD peptide-functionalized reversibly core-crosslinked multifunctional poly(ethylene glycol)-b-poly(epsiloncaprolactone) micelles. Acta Biomater. 2017;50:396-406.

25. Mu D, Li J, Qi Y, Sun X, Liu Y, Shen S, Li Y, Xu B, Zhang B. Hyaluronic acid-coated polymeric micelles with hydrogen peroxide scavenging to encapsulate statins for alleviating atherosclerosis. J Nanobiotechnol. 2020;18:179.

26. Brekken RA, Overholser JP, Stastny VA, Waltenberger J, Minna JD, Thorpe PE. Selective inhibition of vascular endothelial growth factor (VEGF) receptor 2 (KDR/Flk-1) activity by a monoclonal anti-VEGF antibody blocks tumor growth in mice. Cancer Res. 2000;60:5117-24.

27. Noonberg SB, Benz DCC. Tyrosine kinase inhibitors targeted to the epidermal growth factor receptor subfamily. Drugs. 2000;59:753-67.

28. Pant K, Neuber C, Zarschler K, Wodtke J, Meister S, Haag R, Pietzsch J, Stephan H. Active tumor targeting: active targeting of dendritic polyglycerols for diagnostic cancer imaging. Small. 2020;16:1905013.

29. Allen TM. Ligand-targeted therapeutics in anticancer therapy. Nat Rev Cancer. 2002;2:750-63.

30. Fang RH, Kroll AV, Gao W, Zhang L. Cell membrane coating nanotechnology. Adv Mater. 2018;30:1706759.

31. Akhtari J, Rezayat SM, Teymouri M, Alavizadeh SH, Gheybi F, Badiee A, Jaafari MR. Targeting, bio distributive and tumor growth inhibiting characterization of anti-HER2 affibody coupling to liposomal doxorubicin using BALB/C mice bearing TUBO tumors. Int J Pharmaceut. 2016;505:89-95.

32. Simeon R, Chen Z. In vitro-engineered non-antibody protein therapeutics, Protein Cell. 2018;9:3-14.

33. Friedman M, Stahl S. Engineered affinity proteins for tumour-targeting applications. Biotechnol Appl Bioc. 2009;53:1-29.

34. Lendel C, Dogan J, Hard T. Structural basis for molecular recognition in an affibody:affibody complex. J Mol Biol. 2006;359:1293-304.

35. Cui L, Zhang F, Wang Q, Lin H, Yang C, Zhang T, Tong R, An N, Qu F. NIR light responsive core-shell nanocontainers for drug delivery. J Mater Chem B. 2015;3:7046-54.

36. Orlova A, Feldwisch J, Abrahmsen L, Tolmachev V. Update: affibody molecules for molecular imaging and therapy for cancer. Cancer Biother Radio. 2007;22:573-84.

37. Lofblom J, Feldwisch J, Tolmachev V, Carlsson J, Stahl S, Frejd FY. Affibody molecules: engineered proteins for therapeutic, diagnostic and biotechnological applications. FEBS Lett. 2010;584:2670-80.

38. Wikman M, Steffen AC, Gunneriusson E, Tolmachev V, Adams GP, Carlsson J, Stahl S. Selection and characterization of HER2/neu-binding affibody ligands. Protein Eng Des Sel. 2004;17:455-62.

39. Orlova A, Magnusson M, Eriksson TL, Nilsson M, Larsson B, HoidenGuthenberg I, Widstrom C, Carlsson J, Tolmachev V, Stahl S, Nilsson FY. Tumor imaging using a picomolar affinity HER2 binding affibody molecule. Cancer Res. 2006;66:4339-48.

40. Feldwisch J, Tolmachev V, Lendel C, Herne N, Sjoberg A, Larsson B, Rosik D, Lindqvist E, Fant G, Hoiden-Guthenberg I, et al. Design of an optimized scaffold for affibody molecules. J Mol Biol. 2010;398:232-47.

41. Ahlgren S, Orlova A, Wallberg H, Hansson M, Sandstrom M, Lewsley R, Wennborg A, Abrahmsen L, Tolmachev V, Feldwisch J. Targeting of HER2expressing tumors using $111 \mathrm{ln}$-ABY-025, a second-generation affibody molecule with a fundamentally reengineered scaffold. J Nucl Med. 2010;51:1131-8.

42. Sandstrom M, Lindskog K, Velikyan I, Wennborg A, Feldwisch J, Sandberg D, Tolmachev V, Orlova A, Sorensen JN, Carlsson J. Biodistribution and 
radiation dosimetry of the anti-HER2 affibody molecule 68Ga-ABY-025 in breast cancer patients. J Nucl Med. 2016;57:867-71.

43. Cheng W, Zeng X, Chen H, Li Z, Zeng W, Mei L, Zhao Y. Versatile polydopamine platforms: synthesis and promising applications for surface modification and advanced nanomedicine. ACS Nano. 2019;13:8537-65.

44. Cheng W, Liang C, Xu L, Liu G, Gao N, Tao W, Luo L, Zuo Y, Wang X, Zhang $X$. TPGS-functionalized polydopamine-modified mesoporous silica as drug nanocarriers for enhanced lung cancer chemotherapy against multidrug resistance. Small. 2017;29:1700623.

45. Bao X, Zhao J, Sun J, Hu M, Yang X. Polydopamine nanoparticles as efficient scavengers for reactive oxygen species in periodontal disease. ACS Nano. 2018;12:8882-92.

46. Shi Q, Tao Z, Yang H, Fan Q, Wei D, Wan L, Lu X. PDGFRß-specific affibody-directed delivery of a photosensitizer, IR700, is efficient for vascular-targeted photodynamic therapy of colorectal cancer. Drug Deliv. 2017:24:1818-30.

47. Tao Z, Yang H, Shi Q, Fan Q, Wan L, Lu X. Targeted delivery to tumorassociated pericytes via an affibody with high affinity for PDGFRbeta enhances the in vivo antitumor effects of human TRAIL. Theranostics. 2017;7:2261-76.

48. Zhang $H$, Wang $Y$, Wu Y, Jiang $X$, Tao Y, Yao Y, Peng Y, Chen X, Fu Y, Yu L, et al. Therapeutic potential of an anti-HER2 single chain antibody-DM1 conjugates for the treatment of HER2-positive cancer. Signal Transduct Tar. 2017;2:17015.

49. Kim H, Kim S, Park C, Lee H, Park HJ, Kim C. Glutathione-induced intracellular release of guests from mesoporous silica nanocontainers with cyclodextrin gatekeepers. Adv Mater. 2010;22:4280-3.
50. Orlova A, Magnusson M, Eriksson TL, Nilsson M, Nilsson FY. Tumor imaging using a picomolar affinity HER2 binding affibody molecule. Cancer Res. 2006;66:4339-48.

51. Peng L, Hung CT, Wang S, Zhang X, Zhu X, Zhao Z, Wang C, Tang Y, Li W, Zhao $D$. Versatile nanoemulsion assembly approach to synthesize functional mesoporous carbon nanospheres with tunable pore sizes and architectures. J Am Chem Soc. 2019;141:7073-80.

52. Fan $\mathrm{Q}$, Tao Z, Yang H, Shi Q, Wang H, Jia D, Wan L, Zhang J, Cheng J, Lu X. Modulation of pericytes by a fusion protein comprising of a PDGFRbetaantagonistic affibody and TNFalpha induces tumor vessel normalization and improves chemotherapy. J Control Release. 2019;302:63-78.

53. Das MK, Sarma A, Deka T. Polydopamine-based simple and versatile surface modification of polymeric nano drug carriers. ACS Nano. 2014;8:3347-56.

54. Han X, Xu Y, Li Y, Zhao X, Zhang Y, Min H, Qi Y, Anderson GJ, You L, Zhao Y, Nie G. An extendable star-like nanoplatform for functional and anatomical imaging-guided photothermal oncotherapy. ACS Nano. 2019;13:4379-91.

\section{Publisher's Note}

Springer Nature remains neutral with regard to jurisdictional claims in published maps and institutional affiliations.
Ready to submit your research? Choose BMC and benefit from:

- fast, convenient online submission

- thorough peer review by experienced researchers in your field

- rapid publication on acceptance

- support for research data, including large and complex data types

- gold Open Access which fosters wider collaboration and increased citations

- maximum visibility for your research: over $100 \mathrm{M}$ website views per year

At BMC, research is always in progress.

Learn more biomedcentral.com/submissions 